\title{
Discrete choice experiments in the analysis of consumers' preferences for finfish products: A systematic literature review
}

\author{
Javier Cantillo*, Juan Carlos Martín, Concepción Román \\ University of Las Palmas de Gran Canaria, Institute of Tourism and Sustainable Economic Development, Las Palmas de Gran Canaria, Spain
}

\section{A R T I C L E I N F O}

\section{Keywords:}

Finfish

Consumers' preferences

Discrete choice experiments

DCE

Systematic literature review

\begin{abstract}
A B S T R A C T
Discrete choice experiments (DCEs) have become an important tool for assessing the preferences of consumers for finfish seafood products. This investigation presents a systematic literature review of studies performed in the last 20 years (2000-2019) that use DCEs to analyse consumers' preferences for finfish products, with the purpose to identify the main insights of consumer behaviour towards these products, the most used attributes for this type of experiments and to discuss and compare some willingness to pay estimations. We found that origin was the most used attribute for this kind of experiments, while other important factors were the harvest method, a specific certification label and the species or products considered. The WTP estimates evidenced that consumers are willing to pay premiums for domestic products, while similarly, wild products were preferred over farmed products. Also, there were higher WTP estimates for certified products, in which specific certification labels were better options rather than just claiming that the product was certified or not. All claims and labels related to sustainability, nutritional, health and safety information provided premiums that consumers were willing to pay, however, the importance differed depending on the type of label or claim, the country and species. Future research should consider the influence of being or not the main purchaser in the household, as it might affect the WTP values. Also, given the importance, future research extensions using DCEs are needed on the Chinese and Asian finfish market.
\end{abstract}

\section{Introduction}

In the last 60 years, there has been an impressive growth of global fish consumption, starting from $9 \mathrm{~kg}$ /capita in 1961 to $20 \mathrm{~kg} /$ capita in 2016; which has doubled the average annual growth of the population in the same period (FAO, 2018a). The growth in the consumption pattern is related to different factors, but amongst them, the significant growth of fish production is highlighted, and particularly, the one associated with aquaculture farming. In fact, aquaculture has grown its production from around 10 million of tonnes per year in the late 1980s to 80 million of tonnes in 2016; while since the late 1980s, the production of capture fishery has remained more stable around 90 million of tonnes (FAO, 2018a).

However, the consumption patterns differed between different regions as fish consumption depends on economic, cultural and geographic factors. Thus, while developing countries have grown from 6 to $19.3 \mathrm{~kg} /$ capita between 1961 and 2015, in the same period the lowincome countries have only gone from just 3.4 to $7.7 \mathrm{~kg} / \mathrm{capita}$; which are both still far from the value of developed countries in 2015 of $24.9 \mathrm{~kg} /$ capita (FAO, 2018a). At the regional level, Asia has the highest share of fish consumption with 105.6 million (out of the 148.8 total in the world) and one the highest consumption per capita of fish alongside Oceania; while China itself consumes 55.9 million of tonnes of fish and has an average consumption of $41 \mathrm{~kg} /$ capita. The growth in consumption in Asian countries (especially China), can be explained by the raising of the urban population, the growth of fish aquaculture production, higher incomes and increased international fish trade; while the low consumption of some countries and regions rely mostly on limitations on fish production (low technology and infrastructure), lowincome levels and poor marketing and distribution channels, being mostly forced to commercialize the products in the same regions in which they are farmed or captured (FAO, 2018a). On the other hand, Africa and Latin America have the lowest consumption per capita with around $10 \mathrm{~kg}$ (FAO, 2018a).

Among the different groups of seafood, finfish represent the most important group with a total production of 131.4 tonnes (58.8\% coming from capture fisheries and $41.2 \%$ coming from aquaculture), surpassing vastly the production of crustaceans and mollusc with 14.6 and 23.4 millions of tonnes, respectively (FAO, 2018b). Given the importance of the finfish market, the finfish consumers' preferences analysis is also

\footnotetext{
* Corresponding author.

E-mail addresses: javier.cantillo101@alu.ulpgc.es (J. Cantillo), jcarlos.martin@ulpgc.es (J.C. Martín), concepcion.roman@ulpgc.es (C. Román).
} 
relevant for many reasons, including the possibility to estimate the willingness to pay (WTP) for certain product attributes, which is necessary for producers on their market decisions is highly relevant amongst others. Also, according to Olesen, Alfnes, Røra, and Kolstad (2010), if fish products can be labelled and efficiently marketed as being produced under more environmentally friendly conditions or that involve better welfare for the fish, and consumers are willing to pay for such attributes, producers can ask a price premium for those attributes.

Although many methodologies such as contingent valuation method (Haghiri, 2014; Zander \& Feucht, 2018), analytic hierarchical process (AHP) (Lembo, Jokumsen, Spedicato, Facchini, \& Bitetto, 2018; Whitmarsh \& Palmieri, 2011, 2009), conjoint analysis (Altintzoglou, Verbeke, Vanhonacker, \& Luten, 2010; Claret et al., 2012; Hill, Nelson, Woods, Weese, \& Whitis, 2013), focus groups (Claret et al., 2014, 2012; Schlag \& Ystgaard, 2013), self-administered questionnaire (Ramalho Ribeiro et al., 2019; Tomić, Lucević, Tomljanović, \& Matulić, 2017), factor analysis (Hall \& Amberg, 2013) and cluster analysis (Polymeros, Kaimakoudi, Schinaraki, \& Batzios, 2015) have been used to study the preferences of consumers for finfish products; most of these methodologies employed elicit consumers' preference information based on data that do not conform to standard neoclassical economic theory. In contrast, DCEs are rooted in a well-tested theory of choice behaviour, the random utility theory (RUT) (Louviere, Flynn, \& Carson, 2010).

Moreover, DCEs are gaining popularity due to the resemblance of real market decision-making settings (Ankamah-Yeboah, Jacobsen, \& Olsen, 2018). Also, Bronnmann and Hoffmann (2018) declare that DCEs have become a common tool to reveal the determinants of consumers buying behaviour that allow researchers to estimate the WTP for a specific product attribute; while Zander, Risius, Feucht, Janssen, and Hamm (2018) and Louviere, Hensher, Swait, and Adamowicz (2000) also agreed that choice experiments are a well-established method for analysing the preferences of consumers because they are close to real buying decisions and therefore, they generate results that reflect consumers' real buying behaviour.

To our best knowledge, despite the high number of studies that analyse consumers' preferences for finfish, there are just a few studies that summarize and identify patterns and similarities between the heterogeneous findings in each of them. So far, the only attempt to undertake a review of papers related to fish preferences is the work by Carlucci et al. (2015) with a focus on both seafood consumers' preferences and drivers and barriers to fish consumption, independently of the used methodology. The current study differs from the one by Carlucci et al. (2015) in three important issues: (1) the analysis only considers papers that deal with finfish products; (2) the papers under analysis are only based on the use of DCEs and, thus, only three studies out of the 49 papers analysed by Carlucci et al. (2015) are considered here; and (3) the current study presents an overview of the important WTP estimates.

The purpose of this systematic review is threefold: (1) to determine the main findings and the most important attributes used on DCEs that analyse consumers' preferences for finfish; (2) to summarize the WTP estimates of different attributes; and (3) to obtain important insights for the industry and academics. Specifically, this systematic review addresses the research question: which are the most important characteristics and results of the DCEs that analyse the preferences for finfish species in terms of the experiments, the findings and the WTP figures?

This review follows the definition of a systematic review proposed by Moher, Liberati, Tetzlaff, Altman, and PRISMA Group (2009), as it formulated a clear question that uses specific and explicit methods to determine the extraction and analysis of the data. Besides, it satisfies the requirements for systematic reviews that were summarized by Robinson and Lowe (2015) in an attempt to differentiate the conventional literature reviews from the systematic ones. Thus, the focus of the review is based on a specific question and the data collection is based on a specific precise search following PRISMA (Preferred Reporting
Items for Systematic Reviews and Meta-Analyses) as the method for data extraction (Moher et al., 2009). PRISMA is becoming a popular method to conduct systematic literature reviews (Vecchio \& Cavallo, 2019; Wilson, Buckley, Buckley, \& Bogomolova, 2016)

The remainder of the paper is organized as follows: Section 2 presents a concise literature review of discrete choice experiments, Section 3 explains the methodology used for the systematic review, Section 4 offers the results and discussion of the main findings regarding consumers' preferences for finfish depending on the attributes, and some comparisons and relevant aspects of the WTP estimates of some of the papers considered. Finally, Section 5 offers some concluding remarks and exposed some insights for the industry and academics.

\section{Discrete choice experiments}

DCEs represent a common stated preference technique to obtain individual's preferences over different hypothetical alternative scenarios. They are increasingly used to better understand consumers' preferences in different fields, such as health economics (Clark, Determann, Petrou, Moro, \& de Bekker-Grob, 2014; de Bekker-Grob, Ryan, \& Gerard, 2012); transportation (Ben-Elia \& Shiftan, 2010; González et al., 2018; Jensen, Cherchi, \& Mabit, 2013; Rizzi \& Ortúzar, 2003); tourism (Kelly, Haider, Williams, \& Englund, 2007; Martín, Román, \& Mendoza, 2018); the food sector (Ortega, Wang, Wu, \& Olynk, 2011); environmental sciences (Hoyos, 2010); energy efficiency (Banfi, Farsi, Filippini, \& Jakob, 2008); and agricultural economics (Rigby \& Burton, 2005). In them, with the aid of specifically designed surveys, respondents must choose between two or more alternatives that are specified by systematically altering attribute levels using some experimental design method. Choices made by respondents reveal important information about the underlying individual's utility which can be later estimated using choice modelling techniques.

DCEs are an excellent tool for determining the relative importance of different attributes and levels in the decision making, and for calculating trade-offs between them. For this reason, the methodology has been extensively used for research and policy. Moreover, DCEs are particularly valuable because they allow to include new products or attributes that do not exist in the real market, and for which there is no data available. Also, DCEs, in some cases, can be used for demand prediction, while they are also valuable when data from real markets is unobtainable because the direct observation of consumers making choices is impossible. Finally, DCEs allow obtaining willingness to pay estimates for different attributes when a cost attribute is included in the experiment, which can be useful for a cost-benefit analysis.

This technique combines consumer theory, experimental design theory and econometric analysis, and it is grounded on the random utility theory (RUT) (McFadden, 1974; Thurstone, 1927) and Lancaster's theory (Lancaster, 1966). On one hand, the RUT suggests that individuals associate a utility to each choice alternative and considering the utility maximization behavioural rule, consumers choose the alternative that offers them the highest utility. The utility is a latent construct that cannot be observed by the researcher (Louviere et al., 2010). Thus, it is represented by a systematic or measurable part and a random component. On the other hand, Lancaster's theory establishes that products and services can be described using a set of characteristics (attributes). Therefore, the systematic utility can be represented by the attributes and their levels, as well as the individual's characteristics. Meanwhile, the random component consists of an error term that is related to the unobserved preference variation (Domencich \& McFadden, 1975). The error term can also be defined as the difference between the real utility and the utility captured by the estimated model (Train, 2009). More formally, considering that $V_{i q}$ is the systematic utility of alternative $i$ for individual $q$ and $\varepsilon_{i q}$ is the random component associated with alternative $i$ and individual $q$; the utility of alternative $i$ for individual $q\left(U_{i q}\right)$ is represented as follows: 
$U_{i q}=V_{i q}+\varepsilon_{i q}$

Since $U_{i q}$ is a random variable, the model cannot predict which exact alternative the individual will choose, but the probability with which it will be chosen. Thus, assuming a certain probability distribution for the error terms, different discrete choice models can be derived. The Multinomial Logit model (MNL), which is by far one of the most widely used, is obtained when the error terms are iid extreme value. In this case, the choice probabilities $P_{i q}$ can be easily calculated and are represented as:

$P_{i q}=\frac{e^{V_{i q}}}{\sum_{j} e^{V_{j q}}}$

The MNL model exhibits the independence from irrelevant alternatives property, which make its use inappropriate to model choice situations when particular substitution patterns exist. More flexible models such as those of the Mixed logit (ML) family can be used in these particular cases. Thanks to the huge improvement in the computational techniques during recent decades, ML models have become very popular in modelling choice behaviour. Given their flexibility, they can approximate any random utility model and overcome the main limitations of the MNL. Thus, under the ML approach, it is possible to cope with random taste heterogeneity, unrestricted substitution patterns and the panel correlation effect inherent to stated choice data. A complete reference guide for the different discrete choice models can be consulted in Train (2009).

Willingness to pay figures can be derived from discrete choice models when the cost or price attribute is included in the experiment. They quantify, in monetary terms, the changes produced in the individual's utility due to a change in the level of a particular attribute. WTP figures are obtained as the ratio between the marginal utility of the attribute and the marginal utility of income which, in turn, is defined as the negative of the marginal utility of the cost (McFadden, 1981). Thus, considering that $X_{i k}$ is the attribute $\mathrm{k}$ of alternative I, $C_{i}$ is the cost of alternative $\mathrm{i}$ and $V_{i}$ is the estimated utility of alternative I; the WTP for improving the attribute $k$ of alternative $i$ is defined as:

$W T P_{X_{i k}}=\frac{\partial V_{i} / \partial X_{i k}}{\partial V_{i} / \partial C_{i}}$

When $V_{i}$ adopts the linear-in-the-parameter functional form, and coefficients are fixed, the computation of the WTP is very simple as it is obtained as the ratio between the coefficient of the respective attribute and the cost coefficient. In contrast, when random coefficients are considered, obtaining the WTP figures becomes more complex as the WTP expressions are usually the ratio of two random variables and, in many cases, they have an unknown probability distribution. In these cases, the posterior estimation of individual level parameters is a good solution to obtain the WTP figures at the individual level (see Train (2009) for a further discussion).

\section{Methods}

In October 2019, we conducted a systematic review of papers that analysed consumers' preferences for finfish by using DCEs. This systematic review followed as much as possible the PRISMA statement, which is recommended for the transparent and improved reporting of systematic reviews, and is applicable to different research areas (Moher et al., 2009). For ease of exposition and clarification, the PRISMA method is summarized in the next section.

\subsection{Identification of eligible publications}

We used SCOPUS as the database because it is the world's largest online abstract and citation database of peer-reviewed literature. To be included as part of the eligible publications, the studies must have presented original research using DCEs to investigate consumer preferences for finfish. Thus, the publication needed to consider at least partially the species of finfish. Also, all the studies must have been available in English. Review articles were excluded from this systematic review since only original publications were considered. Moreover, the papers that assess preferences for recreational fishing were not considered, as well as the studies assessing exclusively other species different from finfish, like crustaceans, molluscs and others. Also, we just considered the studies performed in the last 20 years (2000-2019), pondering that previous information would be probably obsolete in line with aquaculture evolution.

\subsection{Search strategy}

We conducted a search in the abstract, title and keywords on Scopus using the keywords shown in Table 1, in which the search strategy was based in agreement with the SPICE (Setting, Population, Intervention, Comparison, Evaluation) framework (Booth, 2006). Also, we added on the intervention element the term "conjoint analysis" because many publications are wrongly designated as it when they are truly using a DCE. The misleading terminology has the origin in the 1980s when some scholars suggest that DCEs were just another form of conjoint analysis. Louviere et al. (2010) clarify that DCEs are very different from conjoint analysis because the former is mainly based on RUT and the latter are not grounded in any behavioural or choice theory. As the authors recognize "Academics and practitioners often seem to confuse both paradigms .... Indeed, we believe that many researchers who claim

Table 1

Application of the SPICE framework.

\begin{tabular}{|c|c|c|}
\hline SPICE element & Search terms assigned & Reason \\
\hline Setting - where? & No term assigned & The interests of the review include all contexts \\
\hline Population - for whom? & $\begin{array}{l}\text { Consumer } \\
\text { Public }\end{array}$ & Limit the information to just consumers and the public in general \\
\hline Intervention - what? & $\begin{array}{l}\text { Choice experiment } \\
\text { Discrete choice } \\
\text { Stated choice } \\
\text { Conjoint analysis }\end{array}$ & The intervention of interests is the discrete choice experiments \\
\hline Comparison - compared with what? & No term assigned & Not interested in comparing different methodologies or products \\
\hline Evaluation - with what result? & $\begin{array}{l}\text { Aquaculture } \\
\text { Seafood } \\
\text { Farmed fish } \\
\text { Salmon } \\
\text { Tilapia } \\
\text { Trout } \\
\text { Turbot } \\
\text { Seabass } \\
\text { Seabream }\end{array}$ & The outcomes of interest are the choices for finfish products \\
\hline
\end{tabular}


to apply conjoint analysis really are using DCEs" (p. 58).

Finally, to introduce the information on the search section of the SCOPUS database, the keywords previously specified were combined using the operator "OR" between terms and the operator "AND" between different SPICE elements. Thus, the full syntax entered into the database was (aquaculture OR seafood OR (farmed AND fish) OR salmon OR tilapia OR trout OR turbot OR seabass OR seabream) AND ((choice AND experiment) OR (discrete AND choice) OR (stated AND choice) OR (conjoint AND analysis)) AND (consumer OR public).

\subsection{Coding and data synthesis}

The publications extracted from the search on SCOPUS were in a first stage reviewed just by their abstracts and those that did not meet the requirements to be eligible were excluded. After that, the remaining publications were full text reviewed to determine if they fulfil the criteria and if so, they were considered for the present investigation. Thus, it is important to highlight that during all the screening processes, the papers were reviewed independently by the three authors, following the previously described inclusion criteria. Then, the divergences were solved by discussing the differences, and the inclusion standards were finally agreed by all authors.

Furthermore, for those studies that meet the criteria, we recorded the year of publication, the authors, the name of the paper, the models applied, the species considered, the country of location of the study and the journal (see Appendix A). In addition, to understand better the implication of the different attributes in the experiments, the studies were classified in different categories which were proposed and discussed between the authors (Fig. 1). They were divided into two groups depending on the aim of the investigation in market competition papers and market innovation papers, in which, the first category looks to identify the most important factors affecting the buying decision of consumers in real markets, while the second addresses the level of motivation that consumers have for the implementation of new products that are not still available in real markets or they are not still wellknown by the consumers. We name this category as innovation because as Thong and Solgaard (2017) recognize, product innovation in fishery and aquaculture should be directed to make seafood more convenient and attractive.

Second, in each category, the studies were further classified in different subcategories. In the case of the real markets or market competition, the categorization was done in two stages. The first stage divides the papers into two subcategories according to whether the experiment includes prior information or not. The second stage divides the papers into three potential subcategories according to whether the experiment includes: (1) only wild species; (2) wild vs. farmed species; and (3) only farmed species.

Similarly, For the market innovation papers, we follow the classification proposed by Joffre, Klerkx, Dickson, and Verdegem (2017). The authors analyse aquaculture innovation through a systematic literature review using three main bodies of knowledge that conceptualize and manage innovation: Technology-driven, Systemic, and Business and Managerial approaches. Technological innovations include new breeding systems, feeds, and vaccines. Systemic innovation encompasses different product transformations and institutional frameworks such as standards, regulations, and laws. And finally, business and managerial innovation approaches include new product developments and open innovation which can rely on external researchers and

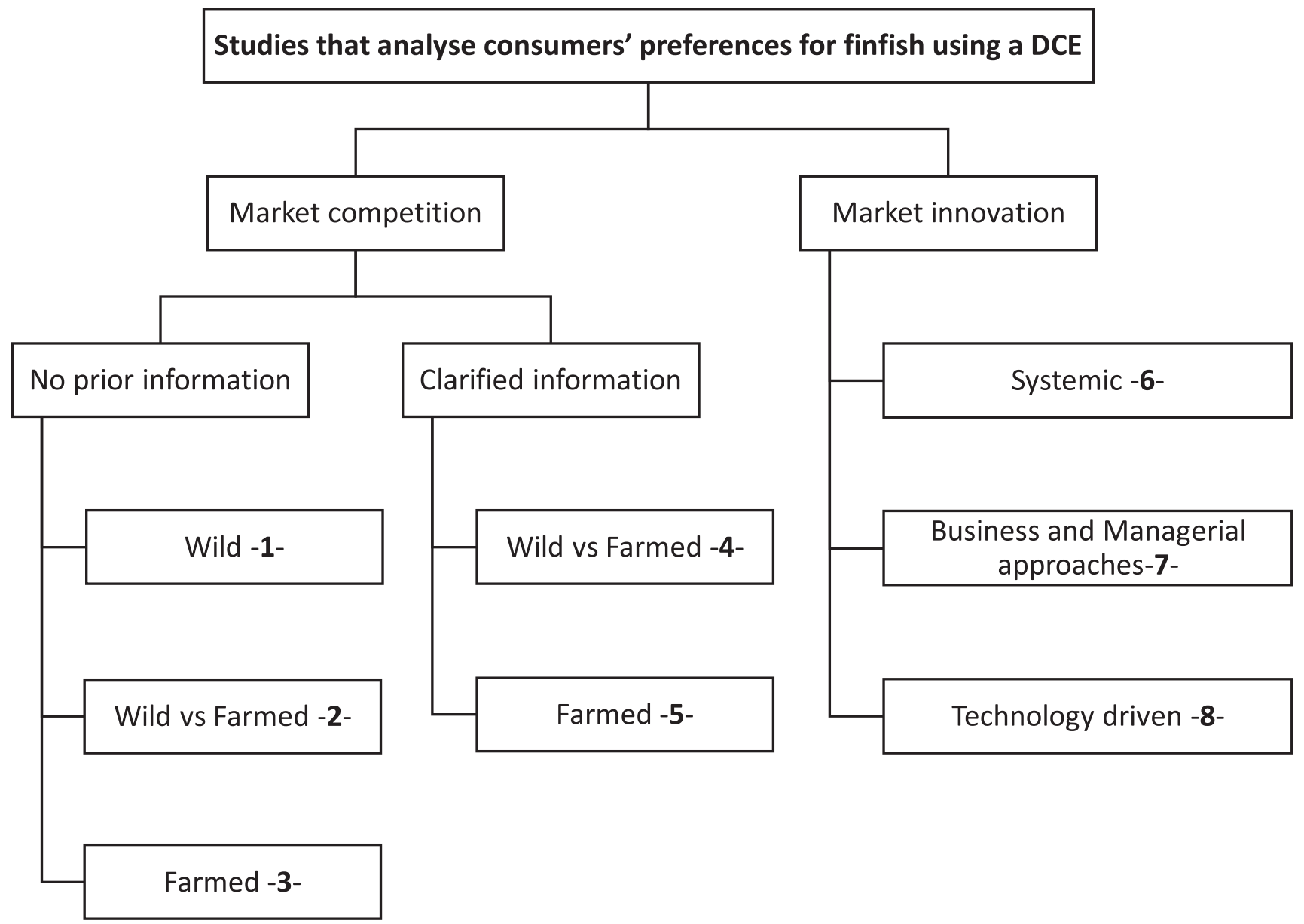

Fig. 1. The classification of the papers. 

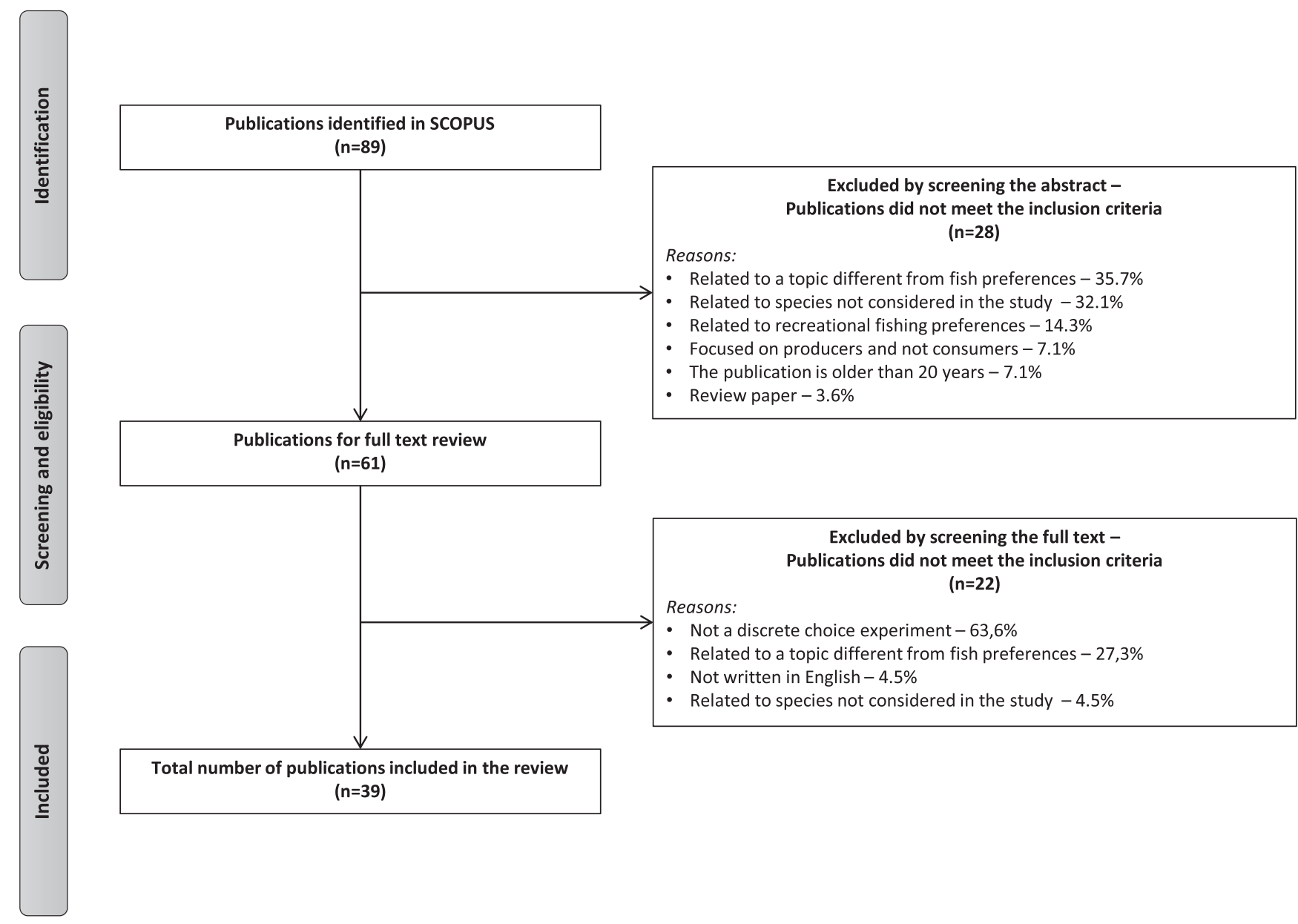

Fig. 2. Flow chart through the different steps to select the studies.

partnerships that resolve specific problems.

Finally, the attributes used in each of the experiments were extracted and generalized to identify the main attributes of this kind of experiments and the frequency of appearance for each paper category and in general. Also, we extracted the results of some WTP estimates found in the selected studies to establish some similarities and relevant conclusions on the different attributes studied in the publications.

\section{Results and discussion}

This section presents and discusses the main search results, main findings obtained from the analysed studies, main attributes used for this kind of experiments and their respective frequencies, and some WTP estimates comparisons between the different analysed papers.

\subsection{Search results}

Fig. 2 shows a flow chart of the different steps through the selection of the publications. Initially, 89 publications were detected from the search process to be candidates for inclusion in the review. Afterwards, 28 publications were removed after the abstract screening process, where the main reasons for exclusion were related to species not considered in the study like shrimp, oysters, mussels etc; or because they were related to a topic different from fish preferences. Similarly, for the remaining papers, after screening the full text, 22 were excluded mainly because the paper was not based on a discrete choice experiment or because it was related to a topic different from fish preferences. The final list included 39 papers (Table 2 - Appendix A), from which 31 publications $(79.5 \%)$ were associated to the market competition category, while the remaining $8(20,5 \%)$ were assigned to the category of market innovation.

In the market competition category, 23 papers (74.2\%) did not include prior information for the experiment; 9 were related to wildcaught fish independently, 6 included a wild vs farmed analysis and the remaining 8 focused exclusively on farmed fish. On the other hand, the other 8 papers $(36.4 \%)$ included clarified information for consumers during the experiment, and while 3 of them focused solely on farmed species, 5 included an analysis of wild versus farmed species. To sum up, in the market competition papers, 9 focus on wild-caught species, 11 included a wild versus farmed analysis and 11 focused only on farmed species. Moreover, in the market innovation category, 2 papers (25\%) were related to technology-driven approaches, 5 papers $(62.5 \%)$ were associated to systemic approaches especially related with labelling and sustainability, and there is an additional paper (12.5\%) included in the business and managerial approaches.

\subsection{Main attributes of the experiments}

One of the main important points of a good experimental design is the selection of the attributes that are going to be included. Table 3 (Appendix B) includes a selection of the attributes found in the literature review included as part of the DCEs in the context of understanding consumers' preferences for finfish. It includes for each attribute the general preference, the papers that incorporated them as well as the species and countries related to those papers. The table also contains the most common levels that were used for each one of the attributes, and the distribution according to the classification that was previously discussed. It is important to notice that Table 3 does not include price as 
an attribute of the experiment as all the papers included it in the experiment as a prerogative because the authors were interested in obtaining WTP. Nevertheless, in marketing, price is considered as an extrinsic attribute that functions as a surrogate for quality when consumers have inadequate information about other intrinsic attributes (Zeithaml, 1988).

Results indicate that the most used attribute was the origin, which was found in 26 out of 39 papers and that refers to the country or region of origin of the product and Its inclusion depends on whether the species considered are also produced in the country studied since this attribute is associated with ethnocentrism. Moreover, other highly used attributes were the harvest method (included in 14 experiments), the specific certification label (included in 13 experiments), the species or products considered (included in 10 experiments), the sustainability claim or level (included in 8 experiments), the production method [organic, conventional, others] (included in 7 experiments) and the processing or storage form (included in 6 experiments). In particular, the attribute of the species or products is incorporated to evaluate if the different attributes indicated different values, tendencies or WTP estimates depending on the species considered.

Among the different attributes, most of them have a clear pattern of general preference except for the type of feed and the place of purchase. For the type of feed, some authors found that it had no impact on the buying choice, while others observed preferences for fish feed with insect protein and vegetal feed. Similarly, for the place of purchase, some authors found that consumers preferred products bought in a specialized store, while other authors concluded that the type of store had no impact on the buying choice.

On the other hand, the clear general preferences observed for those attributes which were at least included in two papers can be summarized as follows: (1) Local products are preferred over imported products; (2) Wild fish are preferred over farmed fish; (3) Specific certified label products (ASC, MSC and Naturland) are preferred over those that do not have any type of certification; (4) Consumers are willing to pay premiums for sustainable produced products that incorporate ecolabels; (5) Preference for alternative production methods (i.e. ASC, IMTA, CCA) over the conventional procedures; (6) Preference for fresh products above other presentations like frozen, smoked, dried or fried; (7) Labelled/certified products are preferred over those that are unlabelled/uncertified; (8) Labels that highlight health and nutritional benefits of finfish consumption like for example a high content of omega 3 or improvement of the heart function are preferred over those that do not include such information; (9) The redder alternatives are preferred, especially the R27 colour from SalmoFan; (10) Preference for fillet presentation, especially with no bones; (11) Governmental certifiers are preferred over not governmental ones and the National Marine Fisheries Services (NMFS) was preferred as a certifier in comparison to the World Wildlife Fund (WWF) and the Marine Stewardship Council (MSC); (12) Safety claim products are preferred over those which do not have any safety claim or label; (13) Bigger fish are preferred; (14) Preference for products that include a generic fair-trade claim over those that do not include any fair-trade claim.

In addition, analysing the attributes according to the proposed categories, we found that the harvest method factor was never included on the market competition papers that consider a wild or farmed analysis independently, as expected. Also, the production method attribute was just found among the market competition papers, in those associated with farmed fish because the main purpose is to analyse whether a more organic production process for farmed species is valued by consumers. Moreover, in the market competition papers in which there is additional clarifying information, the sustainability label was never included considering that the purpose of giving this additional information is to understand its implication on the decision. Lastly, the colour factor was just found on market competition papers that assessed farmed species because this has only been analysed in farmed salmon.

\subsection{Main findings and WTP estimates for the attributes in the experiments}

This section compares the main findings and the WTP estimates obtained from the analysed studies. The WTP estimates were standardized and compiled if possible in euros/ $\mathrm{kg}$ as shown in Tables 4, 5, 6, 7 and 8 , for attributes related to the origin, the production practices, certifications, labels and claims, and presentation and others, respectively, while those in different units were finally compiled in Table 9 (see Appendix C). As exposed by Roheim, Sudhakaran, and Durham (2012), the magnitudes of the WTP estimates should be viewed conservatively as the values are quite high considering the average price of the product, which might be due in part to the hypothetical nature of the experiments. Therefore, readers are advised to view the figures in wide-ranging terms as simple signals of the relative importance of each of attribute levels, as figures depend on many different features such as countries, species, year, attributes included in the experiment and technical characteristics of the sample amongst others.

\subsubsection{Origin}

The origin was found to be the most important attribute for the decision of buying finfish in many studies (Banovic, Reinders, Claret, Guerrero, \& Krystallis, 2019; Lim, Hu, \& Nayga, 2018; Mauracher, Tempesta, \& Vecchiato, 2013; McClenachan, Dissanayake, \& Chen, 2016; Miyata \& Wakamatsu, 2018; Risius, Hamm, \& Janssen, 2019; Stefani, Scarpa, \& Cavicchi, 2012; Thong, Solgaard, Haider, Roth, \& Ravn-Jonsen, 2018; Wakamatsu \& Miyata, 2017). The general pattern shows that the local products are the preferred options (AnkamahYeboah et al., 2019, 2018; Ariji, 2010; Banovic et al., 2019; Davidson, Pan, Hu, \& Poerwanto, 2012; Fernández-Polanco, Loose, \& Luna, 2013; Hinkes \& Schulze-Ehlers, 2018; Jaffry, Pickering, Ghulam, Whitmarsh, \& Wattage, 2004; Lim et al., 2018; Mauracher et al., 2013; McClenachan et al., 2016; Risius et al., 2019, 2017; Rudd, Pelletier, \& Tyedmers, 2011; Stefani et al., 2012; Thong et al., 2018, 2015; Uchida, Onozaka, Morita, \& Managi, 2014; van Osch et al., 2019, 2017; Witkin, Dissanayake, \& McClenachan, 2015; Yip, Knowler, Haider, \& Trenholm, 2017; Zander et al., 2018), which might be due to several reasons such as more trust on local products or the ethnocentrism of consumers (Luomala, 2007; Verlegh \& Steenkamp, 1999). Also, in Germany, local products are preferred because of health and food safety issues (Hinkes \& Schulze-Ehlers, 2018).

The results indicated that Italy showed the highest WTP for local products of Salmon, Seabream and Seabass against imported products (from 11.30 to 18.10 euros $/ \mathrm{kg}$ ). Salmon, Seabream and Seabass were also the species with the highest WTP in general, alongside Trout in Germany. Contrary to that, Tilapia in the US and Salmon in Israel, exhibit the lowest WTP for domestic products compared to imported products. On the other hand, in particular cases, when the origin of the products was related to a place associated to contamination, such as the area around Fukushima (Japan) after the nuclear disaster, the preference for products outside this area were higher, even if they were not local (Miyata \& Wakamatsu, 2018; Wakamatsu \& Miyata, 2017).

\subsubsection{Production process}

The production process preferences are reflected in the studies by the harvest method, the production method, the type of feed and the production practices.

4.3.2.1. Harvest method. Consumers usually prefer wild fish over farmed fish (Ariji, 2010; Bronnmann \& Asche, 2017; Bronnmann \& Hoffmann, 2018; Chen, Alfnes, \& Rickertsen, 2015; Darko, Quagrainie, \& Chenyambuga, 2016; Davidson et al., 2012; Fernández-Polanco et al., 2013; Ferrer Llagostera, Kallas, Reig, \& Amores de Gea, 2019; Jaffry et al., 2004; Roheim et al., 2012; Thong et al., 2018; Thong, Haider, Solgaard, Ravn-Jonsen, \& Roth, 2015; Uchida et al., 2014; Yip et al., 2017). The preferences for wild products occur for different reasons: on one side, consumers often describe farmed fish as being less healthy and 
with lower quality when compared to wild fish (Claret et al., 2014; Verbeke, Sioen, Brunsø, De Henauw, \& Van Camp, 2007), while other key elements that have conditioned the image and acceptance of aquaculture fish are the comparatively lower costs, perception of an artificial-like product, and lack of information on sustainable farming practices (Altintzoglou et al., 2010; Claret et al., 2014; Vanhonacker, Altintzoglou, Luten, \& Verbeke, 2011). Also, Darko et al. (2016) and Davidson et al. (2012) obtained that the preference for wild species was more related to issues like availability and taste, while Schlag and Ystgaard (2013) found that it was due to qualitative non-scientific concerns, such as less trust in farmed products for being perceived as not natural and unfamiliar. Finally, Bronnmann and Asche (2017) concluded that the matters associated with sustainability are more relevant than those associated with quality when wild versus farmed fish preferences are analysed.

In general, we found that consumers are willing to pay premiums for wild fish in comparison with farmed species, and this is especially high for Tuna and Salmon in the US with WTP estimates that range from 8.61 to 18.75 euros $/ \mathrm{kg}$. Moreover, it was found that the information given to consumers can affect critically the valuation of certain attributes' WTP, including the harvest method. In fact, even though the results showed that there are evident heterogeneous perceptions among consumers, in general, it is observed that the given information about the production methods and the certification criteria increased the gap between the WTP of wild vs. farmed fish around 5 euros $/ \mathrm{kg}$, even in the cases where the certification increases the WTP for farmed fish (most of the cases except for ASC in Turbot).

4.3.2.2. Production method. Several studies have addressed the preference for alternative production methods over conventional procedures. Some studies concur that there is a preference for an organic production method (Ankamah-Yeboah, Jacobsen, Olsen, Nielsen, \& Nielsen, 2019; Mauracher et al., 2013; Olesen et al., 2010, 2006; Stefani et al., 2012), while Ankamah-Yeboah et al. (2018) found that consumers of Trout in Germany favour a production method following the Aquaculture Steward Council (ASC) procedures. Moreover, in the US West Coast, Yip et al. (2017) found a preference for salmon produced using integrated multitrophic aquaculture (IMTA) and closed-containment aquaculture (CCA), where the former exhibit higher WTP estimations.

Among the different production methods, the highest WTP values in comparison to a conventional production method were obtained for the production method related to the ASC for Trout in Germany (10.03 euro $/ \mathrm{kg}$ ), followed in order by IMTA for Salmon in the US (6.80 euros/kg) and Organic for Trout in Germany (4.54 euros $/ \mathrm{kg}$ ). These results suggest a high valuation for alternative production methods in Germany for Trout; however, the high value for the ASC production method (Ankamah-Yeboah et al., 2018) might be a little biased considering that the model evidenced a significant interaction effect between the ASC production method and using insect protein as feed, which resulted in a negative WTP of -9.58 euros $/ \mathrm{kg}$.

Regarding the interaction of the information provided and the production method, Ankamah-Yeboah et al. $(2019,2018)$ found that the results are process dependent: (1) more organic labelled information related to fish welfare means a higher WTP; and (2) more environmental information made no significant contribution to the WTP than no adding extra information to the label; (3) adding both welfare and environmental information results into a lower WTP that adding simply the fish welfare information.

4.3.2.3. Type of feed. Stefani et al. (2012), Davidson et al. (2012) and Ankamah-Yeboah et al. (2018) obtained that the buying choice is not much affected by the type of feed for Seabream in Italy, Tuna in the US and Trout in Germany, respectively. Thus, it can be concluded that other feed sources such as insect protein or vegetable can be used to reduce costs if the regulation acts as a facilitator because this type of feed does not affect the WTP. However, Ankamah-Yeboah et al. (2018) also found a negative interaction effect between the ASC production method and using insect protein as feed, which suggests than the type of feed does not affect the WTP as long as the product is not ASC certified. Moreover, Ferrer Llagostera et al. (2019) found that in Spain there is a higher WTP for fish feed with insect protein or vegetal feed over the conventional fish meal (11.89 and 17.20 euros $/ \mathrm{kg}$ respectively), nevertheless, the taste expectation for fish feed with insect is still low (Ferrer Llagostera et al., 2019).

4.3.2.4. Production practices. Regarding production practices for Salmon in Canada, Rudd et al. (2011) found significant WTP associated to production with a low level of contamination (8.57 euros/kg for low levels of polychlorinated biphenyls PCBs against high levels), low local impacts on the environment (2.19 euros/kg against high impacts) and low global impacts on the environment (2.00 euros/kg against high impacts). Meanwhile, Stefani et al. (2012) found that there is a preference for Seabream farmed on marines cages over ponds, with a WTP of 6.75 euros/kg for the former option.

\subsubsection{Certifications}

The literature exposes two different forms of incorporating the impact of the certification labels in the discrete choice experiments. The first one is to specify different recognized certification labels that are normally managed by international or national agencies, while the second form consists of just stipulating if the product is certified/labelled or not.

4.3.3.1. Specific certification label. Many investigations highlight the preference for products that have some specific certified label over those that do not have (Banovic et al., 2019; Bronnmann \& Asche, 2017; Bronnmann \& Hoffmann, 2018; Chen et al., 2015; Hinkes \& SchulzeEhlers, 2018; Jaffry et al., 2004; Lim et al., 2018; McClenachan et al., 2016; Miyata \& Wakamatsu, 2018; Risius et al., 2019, 2017; Wakamatsu \& Miyata, 2017; Zander et al., 2018). On one side, for farmed species, some studies highlight the preferences for the Aquaculture Stewardship Council (ASC) certification label (Banovic et al., 2019; Bronnmann \& Hoffmann, 2018; Risius et al., 2019), which is an international certification exclusively for aquaculture products, for which he highest WTP values were obtained for Turbot and Salmon in Germany, where it can reach up to 18.40 euros $/ \mathrm{kg}$ in comparison to non-certified products. On the other part, for wild-caught species, there is a notorious preference for the certification label related to the Marine Stewardship Council (MSC) (Bronnmann \& Asche, 2017; Lim et al., 2018; McClenachan et al., 2016; Miyata \& Wakamatsu, 2018; Wakamatsu \& Miyata, 2017), which is also an international certification but applies only for wild products. Bronnmann and Hoffmann (2018) obtained the highest WTP for the MSC certification on informed consumers of Turbot in Germany with 33.52 euros $/ \mathrm{kg}$ in comparison to a product not certified.

In addition, the Naturland certification label which applies for both organic aquaculture and sustainable fishery was the preferred option in the studies of Hinkes and Schulze-Ehlers (2018), Risius, Janssen, and Hamm (2017) and Zander et al. (2018), from which Hinkes and Schulze-Ehlers (2018) determined a WTP of 1.62 euros $/ \mathrm{kg}$ for Tilapia and Pangasius carrying this certification in comparison to no-certified products. Also, other certification labels that have been the preferred options for consumers are the French Agriculture Biologique (AB) label for French farmed products (Chen et al., 2015), with an estimated a WTP of 1.84 euros $/ \mathrm{kg}$ for Cod, Salmon, Monkfish and Pangasius, and the sustainable managed fishery for different species in the UK (Jaffry et al., 2004). Moreover, in the case of Japan, the Marine Eco-Label Japan Council (MEL) certification was introduced in some experiments (Miyata \& Wakamatsu, 2018; Wakamatsu \& Miyata, 2017), and the authors found a positive WTP for the certified products; however, the 
MSC certification provided a higher WTP than the MEL label (Wakamatsu \& Miyata, 2017).

Finally, as expected, Chen et al. (2015) determined that providing negative information related to farming practices and the fisheries affect negatively the WTP for specific certification labels. In fact, this negative effect was higher than the opposite effect caused by the positive information provided by the labels which suggested that there was some asymmetry between the negative and positive effects of the eco-labels.

4.3.3.2. Existence of an ecolabel or certification. When the information of the certification of the products is given as an unlabelled alternative with a yes/no option, the general consumers' preference indicates that the labelled/certified products are preferred over those that are not labelled/uncertified (Ariji, 2010; Johnston, Roheim, Joglekar, \& Pomeroy, 2008; Uchida et al., 2014; Yip et al., 2017). For Salmon in the US, the WTP ranged from 0.79 to 3.22 euros $/ \mathrm{kg}$ for certified products over non-certified. Also, it is important to highlight that the interaction between the existence of an ecolabel and alternative production methods like IMTA and CCA also evidenced a premium of 10.02 and 5.96 euros/ $\mathrm{kg}$ respectively, in comparison with products farmed with the same methods that do not include the eco-labels.

4.3.3.3. Certifier or verification entity. The WTP for the certification labels depends also on the association that certifies them (Jaffry et al., 2004; Johnston et al., 2008; Roheim et al., 2012). Jaffry et al. (2004) and Roheim et al. (2012) found that governmental certifiers are preferred against not governmental ones, while Johnston et al. (2008) found that for Cod consumers in the US, the National Marine Fisheries Services (NMFS) was more preferred as certifier than the World Wildlife Fund (WWF) and the Marine Stewardship Council (MSC). Finally, Roheim et al. (2012) identified a WTP for Salmon in the US of 14.04 and 11.43 euros $/ \mathrm{kg}$ for products certified by the government and by an environmental agency, respectively, against not adding information of the certifier.

\subsubsection{Labels and claims}

Labels and claims are mainly used to provide more information to consumers about the products. The most used in the literature are related to sustainability, health and nutritional benefits, safety, fair-trade and others.

4.3.4.1. Sustainability claim or level. van Osch et al. $(2019,2017)$ found that consumers are willing to pay premiums for sustainably farmed products by incorporating an ecolabel that considers different levels of sustainability in a study analysing Salmon and Seabream in different countries of the EU (Ireland, the UK, Italy, Israel and Norway). It was found that the highest WTP for this attribute was associated with the highest level of sustainability in the UK, with a value of 15.18 euros $/ \mathrm{kg}$ in comparison to the lowest level of sustainability. Other authors found that consumers were willing to pay important premiums of around 5 euros $/ \mathrm{kg}$ for sustainability labels or claims related to sustainability fishery (Fernández-Polanco et al., 2013) and Sustainable Ecosystem certification (Fonner \& Sylvia, 2015). Also, Risius et al. (2019, 2017) and Zander et al. (2018) observed a preference for claims of products coming from sustainable production or natural ponds over those that did not include this claim. Despite the previous findings, for the case of Trout in Germany, it was found that the sustainability labels had the less impact as an attribute in the choice experiment, because the actual labels were not much recognized and trusted (Risius et al., 2017).

4.3.4.2. Health and nutritional benefits claim or label. Banovic et al. (2019) found that the preferences for the nutrition and health claims varied across products and countries, being more relevant the nutrition claims. Among the nutrition claims, there is a higher WTP for finfish products that highlights a high content of omega 3 in comparison to those that include no information (Banovic et al., 2019; Bi, House, \& Gao, 2016; Fernández-Polanco et al., 2013) or to those that specify a low content of omega 3 (Rudd et al., 2011). It was found that an Omega 3 label or claim can reach up to a WTP of 4.59 euros $/ \mathrm{kg}$ (FernándezPolanco et al., 2013).

On the other hand, Rudd et al. (2011) determined that there is a higher WTP for claim highlighting health benefits over production practices that enhance environmental performance. Among the health claims, the ones that highlight the improvement of heart function had a higher WTP than the ones which highlight the benefits of the brain function (Banovic et al., 2019), nevertheless, the WTP estimates do not exceed in both cases 1.53 euros/kg. Finally, the study of Lim et al. (2018) evidenced that for canned Tuna in the US there is a higher WTP for health labels (improves heart function) against safety labels (Bisphenol-A (BPA) free label).

4.3.4.3. Other labels and claims. Different studies indicate that consumers are willing to pay premiums of maximum 3.88 euros $/ \mathrm{kg}$ for safety claims such as Anisakis free claim (Fernández-Polanco et al., 2013) and "Meets United States Food and Drug Administration (USFDA) safety Guidelines" (Fonner \& Sylvia, 2015). Similarly, Lim et al. (2018) found that consumers have a higher WTP for a (BPA) free label over not having any claim or label. Moreover, a generic fair-trade claim showed a positive WTP against including no label (Hinkes \& Schulze-Ehlers, 2018; McClenachan et al., 2016), being for Pangasius and Tilapia in Germany of around 1.32 euros $/ \mathrm{kg}$. Other claims or labels that have increased the WTP for finfish products are the ones related to premium quality or harvest by the local population certifications, which evidenced a WTP of 2.64 and 5.07 euros $/ \mathrm{kg}$, respectively, over no claim (Fonner \& Sylvia, 2015). Finally, Witkin et al. (2015) found that there is a WTP of around 3.47 euros $/ \mathrm{kg}$ for a choice label that highlights the product as the best choice in comparison to no label.

\subsubsection{Product presentation and place of purchase}

The product presentation depends on attributes such as the processing or storage from, product form presentation, size, colour, brand and the appearance of the package. Also, the place of purchase might affect the choices of the consumers.

4.3.5.1. Appearance of the product. Regarding the processing or storage form, there is a general preference for fresh products above other presentations like frozen, smoked, dried or fried (Ankamah-Yeboah et al., 2019, 2018; Bronnmann \& Asche, 2017; Bronnmann \& Hoffmann, 2018; Darko et al., 2016; Davidson et al., 2012). The highest WTP for fresh products was found for Tuna in the US with 22.82 euros $/ \mathrm{kg}$ in comparison to frozen products (Davidson et al., 2012). Also, some authors found that the information of production practices and certifications schemes affected the WTP for the processing form, but results were inconsistent because for the case of salmon in Germany the WTP increased by 2.04 euros $/ \mathrm{kg}$ when the information was provided, while for Turbot in Germany the WTP was decreased by 2.16 euros $/ \mathrm{kg}$.

In addition, although the product form is associated primarily to the species considered, some studies highlight the preference for fillet presentation (Ankamah-Yeboah et al., 2019, 2018; Thong et al., 2015) and with no bones (Ankamah-Yeboah et al., 2019, 2018). The highest WTP for this attribute was related to trout fillet with skin and no bones in Germany, reaching up to 12.75 euros $/ \mathrm{kg}$ in comparison to a whole fish. In this case, consumers could save some effort to prepare the finfish for cooking with a time and effort that do not provide satisfaction to the consumers in a form of a leisure activity (Becker, 1965). In addition, the size of the fish matters, prevailing the higher WTP for bigger fish in the case of Tilapia in Tanzania (Darko et al., 2016) and Seabass 
in Italy (Mauracher et al., 2013). On the contrary, the brand of the product had no significant impact on the buying choice (Hinkes \& Schulze-Ehlers, 2018; Jaffry et al., 2004).

Finally, for the particular case of farmed salmon, the redder alternatives are preferred, especially the R27 (SalmoFan scale) and higher (Alfnes, Guttormsen, Steine, \& Kolstad, 2006; Olesen et al., 2010, 2006; Steine, Alfnes, \& Rørå, 2005). Also, the awareness of knowing or not the information related to the artificial origin of the red colour has an impact on the WTP for this attribute. Thus, Steine et al. (2005) found that after knowing the information, the WTP decreased for the options redder than R23; while in the study of Alfnes et al. (2006), the information had no effect for R25 colour and lower options, but increased the WTP for the R27 option and decreased the WTP for the R29 option.

4.3.5.2. Presentation of the package. Heide and Olsen (2017) identified the preferences for consumers of Cod in Norway, regarding the presentation of the packages containing the finfish products. They identified that there is a preference for a black colour package over a silver one, as well as for it having a skin shape rather than being modified atmosphere packaging (MAP) or vacuum packaging.

4.3.5.3. Place of purchase. Ankamah-Yeboah et al. (2018) found that there is a higher WTP of around 3.11 euro $/ \mathrm{kg}$ for finfish products bought in a specialized store, in comparison to those acquired in a supermarket. However, this factor did not have any impact on the study of Ankamah-Yeboah et al. (2019).

\subsubsection{Species or products considered}

Although most multi-attribute studies of demand related to seafood involve only a single species (Thong et al., 2015), the inclusion of a species attribute is convenient as it has many advantages. According to (Yip et al., 2017), the inclusion of a species attribute leads to a more realistic situation in the choice sets considering that the same species might compete against each other within one choice set. Thus, the inclusion of a species attribute presents a number of advantages (Thong et al., 2015): (1) the comparison between different species can be done estimating the intrinsic values associated to each one of them, such as the unique nutritional values of salmon derived by the rich quantity of omega 3, which might be considered by consumers in the real market; (2) the individual effects for each species can be relativized over some species used as a reference value -numeraire species; (3) the confidence intervals for WTP estimations are more adjusted; (4) the implementation of a labelled choice experiment (LCE) is possible, and this type of DCE is more realistic in some choice contexts. Regarding the last advantage, Thong et al. (2018) contend that the interaction between price and different species is better compared by consumers in LCEs, and the unobserved product characteristics preferences by the species can be included in the respective constant term.

Regarding the reviewed studies, authors like Hinkes and SchulzeEhlers (2018), Thong et al. (2018, 2015) and Yip et al. (2017) have compared different alternative species to estimate differences in the preferences of consumers and in their willingness to pay estimates. Results indicate a higher WTP for Pangasius over Tilapia in Germany (Hinkes \& Schulze-Ehlers, 2018) and a higher willingness to pay for an eco-certification farmed Atlantic Salmon over wild Sockeye Salmon in the US (Yip et al., 2017). Moreover, in France, results indicate that preferences amongst species differed considerably as salmon, cod, and saithe were ranked high, while pangasius, oyster, and crab were ranked low (Thong et al., 2015). Similarly, Thong et al. (2018) extend the previous study and find that products with large market shares have also strong market position, except for monkfish, pangasius and oysters.

Some investigations have used the species attribute to evaluate the impact of the introduction of substitutes species in the current market (Chen et al., 2015; Witkin et al., 2015). Chen et al. (2015) consider the inclusion of monkfish and pangasius as expensive and inexpensive substitutes for cod and salmon, respectively. The authors find that wild monkfish was preferred to wild cod, however, farmed pangasius' WTP was considerably lower than the other farmed alternatives of salmon and cod. Similarly, Witkin et al. (2015) compare different locally abundant or underutilized species against well-known and overfish species, obtaining that there is a positive WTP above the mid-range market price for popular species of cod and haddock as well as for the locally abundant and underutilized species of pollock.

Furthermore, some authors have just not compared different species, but seafood products, which might differ apart from the species in the processing or storage form and product form (Jaffry et al., 2004; Miyata \& Wakamatsu, 2018; Wakamatsu \& Miyata, 2017). Finally, other authors like Bi et al. (2016) have evaluated different types of shellfish and finfish, alongside other protein choices such as chicken, beef and pork, to present more realistic scenarios for consumers; finding that the highest-ranked seafood item was the grouper, but was still less preferred than chicken and beef in the US.

\section{Conclusions}

The present systematic review shows a summary of the main findings of the papers that use DCEs to analyse the consumers' preferences for finfish products in the last 21 years. The investigation identifies the most important attributes used in the literature for this kind of experiments and compares the WTP estimates of some of the papers, to draw conclusions for the academics and the industry.

The WTP estimates evidence that consumers are willing to pay premiums for domestic products just by the nature of being local; therefore, producers are advised to invest at least partially in the local market and to highlight the origin of the product if possible, on the package. The advantage of selling domestic products in the local markets, apart from being more appreciated by consumers, is that consumption incurs in fewer and lower supply chain costs. According to the WTP results, Italians producers of Salmon, Seabass and Seabream, and German producers of Trout would benefit the highest from this strategy. On the other hand, for producers that export abroad (especially out of their geopolitical region) a large quantity of their production, it is highly advisable to compensate the disadvantage of competing with local production, by enhancing other attributes such as certifications, labels or claims.

Regarding the harvest method, although there is a negative image for products coming from aquaculture (Zander et al., 2018), there is hope to change this preference, because some studies had concluded that the consumers' knowledge of fish and the aquaculture practices is low (Hinkes \& Schulze-Ehlers, 2018; Risius et al., 2019; Zander et al., 2018). Therefore, stakeholders and producers must invest in marketing campaigns that look to inform the consumers better about the benefits of aquaculture; however, the strategies used on the marketing campaigns must be studied carefully, because Bronnmann and Asche (2017) and Bronnmann and Hoffmann (2018) found for salmon and turbot respectively, that although giving information about the production method and the certification criteria enhances the WTP for the certifications in most cases (except for ASC in Turbot), it also increased the gap of the WTP for wild fish against farmed fish. Nevertheless, in this case, although the gap was related to both environmental and quality concerns, the environmental concerns were a more major issue (Bronnmann \& Asche, 2017); and as a result, producers should focus on highlighting the environmental advantages of aquaculture, like, for example, the ability that farmed fish has to protect the wild fish stock from overfishing, which was supported by the majority of consumers in the study of Bronnmann and Hoffmann (2018).

Moreover, results indicated higher WTP values for alternative production methods, which should motivate producers to pursue 
alternative production practices and to highlight the information of their advantages by using marketing campaigns. However, future research is needed on how to provide the information related to the production method, because although, in most cases, additional information increased the WTP for the alternative production method, Ankamah-Yeboah et al. (2019, 2018) found that not always more information means a higher WTP. Thus, it is essential to distinguish those informational attributes which have a higher WTP. Of course, then producers need to evaluate whether these alternative production methods with the associated informational labels increase or not the benefits.

Judging for the WTP values for alternative types of feed, there would be a good opportunity for producers to use alternative feed sources like insect feed or vegetables, if they represent a cheaper option than the conventional feed, considering that this attribute did not have much impact in the consumers' preferences. In addition, judging for the particular results of Ferrer Llagostera et al. (2019), insect feed might be a suitable strategy to gain some premiums by highlighting this attribute, but more research is needed towards the taste expectations.

The WTP estimates also evidence the importance that the consumers give to externalities related to the environment, considering that they are willing to pay 8.57 euros $/ \mathrm{kg}$ for a decreased level of polychlorinated biphenyls PCBs in salmon farming. Following this, producers that used alternative production methods that somehow reduce the contamination of the environment should explicitly add this information to the product labels, even if the information is already implied by a certification because consumers might pay premiums for this extra information.

Regarding certifications, specific certification labels (the ASC and MSC certifications for farmed and wild fish, respectively) are better options to signal products rather than just claiming that the product is certified or not. Also, the effect of information is relevant when presenting these specific certifications as the certification labels including the information increased the WTP. However, it is recommended to focus on the positive information aspects rather than in the negative information aspects as there is an asymmetrical effect between the positive WTP gains and the negative WTP losses.

Furthermore, all claims and labels provided premiums that consumers were willing to pay, however, their importance differed depending on the type of label or claim. Producers should consider adding this information on the products to look for premiums that consumers are willing to pay. First, there is an opportunity of increasing the WTP by using a sustainability level that indicates the increase in environmental sustainability for using some alternative production method. Also, the nutritional label for the omega 3 content of the fish will offer producers a good opportunity to increase their selling prices because of the higher WTP of consumers.

Even though the presentation of the product depends greatly on the species analysed, some general preferences were extracted and should be followed by producers to increase the WTP of consumers. First, the preferences for fresh products suggest that efforts should be put in optimizing the supply chain of fisheries and farms, to guarantee that more products can be commercialized fresh. Also, fillet presentation is preferred, especially without bones; which demands more research for academics and producers to advance further in the reduction of the vertebral skeletal anomalies, which affect greatly the costs of production and extend the filleting costs, because abnormal fish require manual sorting and hand filleting, considering that they are not fitted to filleting machines (Branson \& Turnbull, 2008). Moreover, for farmed Salmon, in particular, even though of the artificial nature of the colour, producers are invited to keep including it in the production process, because even when consumers were aware of the colour origin, they still preferred the redder options. This preference suggests that to decrease the gap between farmed species and wild species, farmers should try to visually resemble the farmed products as much as possible to the wild products, even though it might depend on an "artificial" process.

Moreover, the attribute associated to the type of species or product is recommended to be implemented in future studies that use this kind of experiments, considering that with its inclusion, is possible to obtain more realistic choice sets, which results in less overestimated WTP estimates (Thong et al., 2015). Also, the inclusion determines the relative importance of each attribute for the different species considered in the experiment, provides more trustable and specific results, which are more useful for the construction of relevant policies by marketers and producers.

In addition, is important to notice that despite Asia, and especially China, is by far the largest market for finfish, we could not find any study that analyses the preferences of consumers for finfish in the area using DCE. In fact, little is known about the consumption preferences of Chinese aquatic products, especially on a disaggregated scale. This can be in part explained because the market research reports conducted by major seafood industries and the statistics for Chinese industry associations are either not easily available or usually available at exorbitant prices (Fabinyi, Liu, Song, \& Li, 2016). Also, the few publications available in English regarding consumers' preferences for seafood in China, use other methodologies such as mean scores, basic statistics and cross-tabulations based on questionnaires and interviews (Fabinyi et al., 2016; Wang, Zhang, Mu, Fu, \& Zhang, 2009), as well as multivariate probit regressions (Xu, Zeng, Fong, Lone, \& Liu, 2012). Thus, future research extensions using DCES are needed on the finfish Chinese market.

Finally, the analysed papers showed that there are still some gaps that need to be addressed to understand better consumers' preferences for farmed finfish products. Amongst them, academics should consider in future studies that analyse the preference of consumers, the influence of being or not the main purchaser in the household, considering that if the respondents are the main fish purchasers in the household, it is expected that WTP would be lower than those respondents who are not the main fish purchasers (Bronnmann \& Asche, 2017; Bronnmann \& Hoffmann, 2018). Also, regarding the presentation of the products, more research is needed to know the preferences of the presentation of the package which might affect the WTP for them. In addition, more species should be analysed in other countries or regions to have a better understanding of the market and future research should focus not only on analysing consumer preferences but also on understanding producers' behaviour, to recognize the market of these products in a more objective and complete perspective.

\section{Funding}

This work is part of a project that has received funding from the European Union's Horizon 2020 research and innovation programme under the Marie Skłodowska-Curie grant agreement No. 766347.

\section{Appendix A. Included publications}

A total of 39 publications was included in the review. Table 2 shows the papers considered for the present study, including the author, title of the paper, species considered, the model used, the location of the study, the classification assigned and whether it included or not a WTP analysis. 


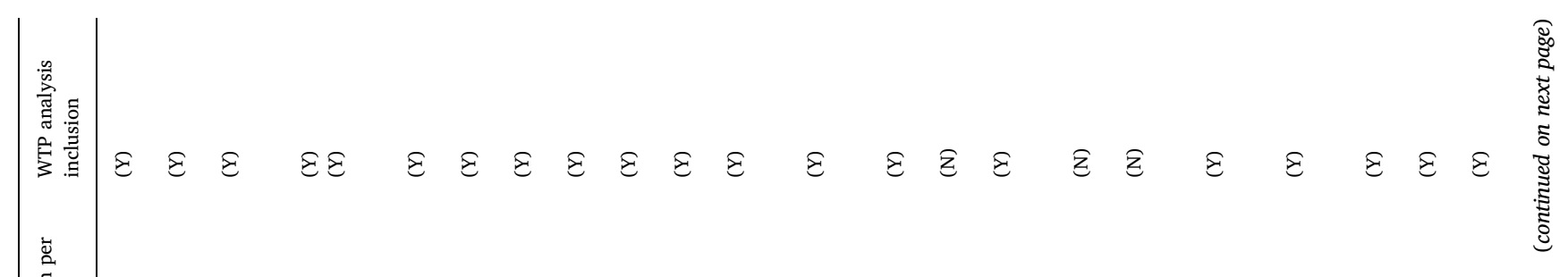

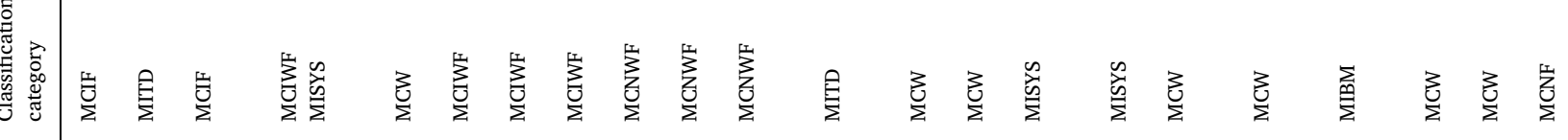

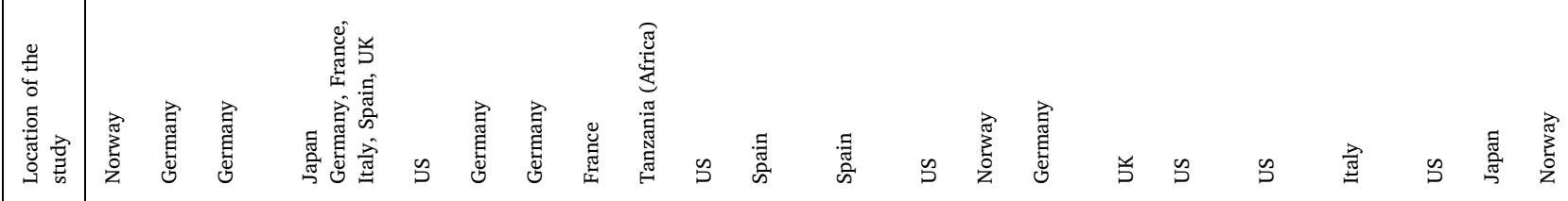
|l|

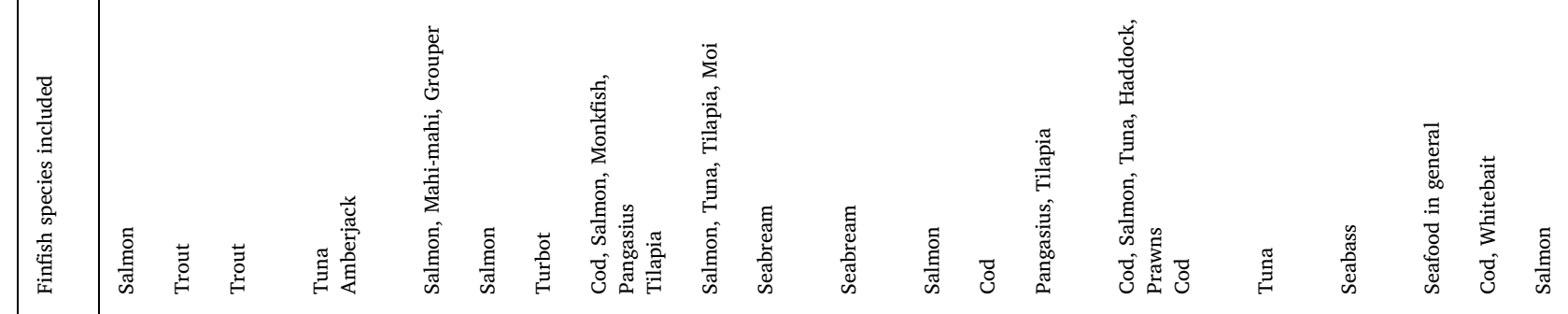

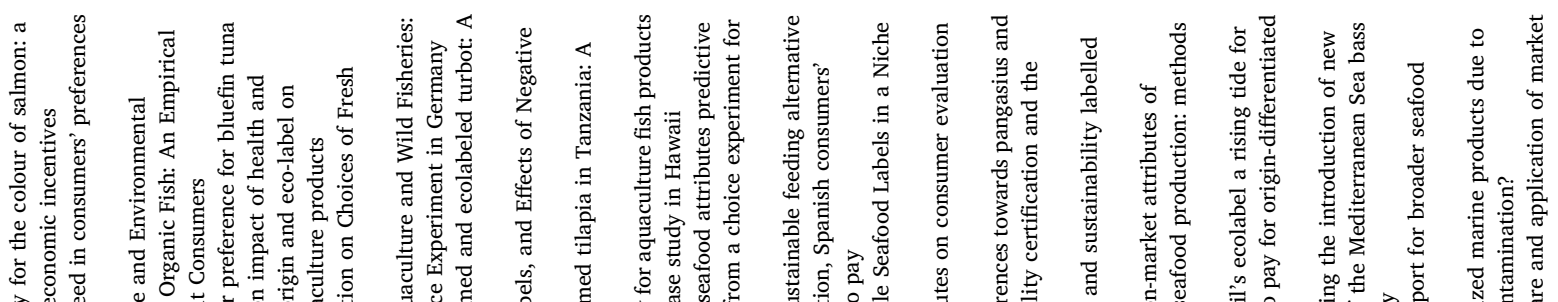

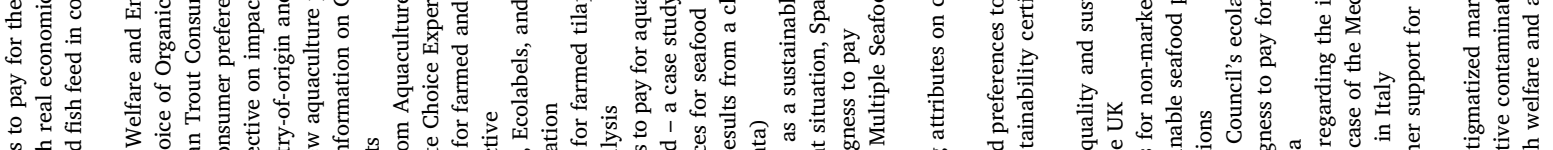

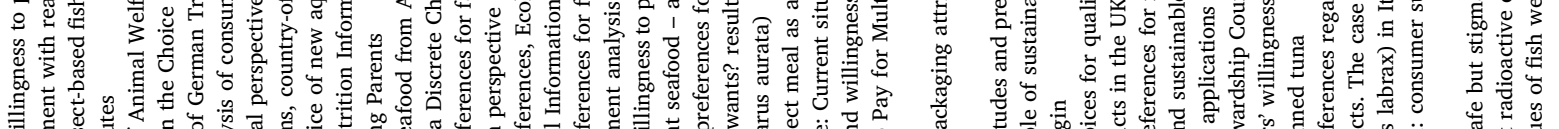

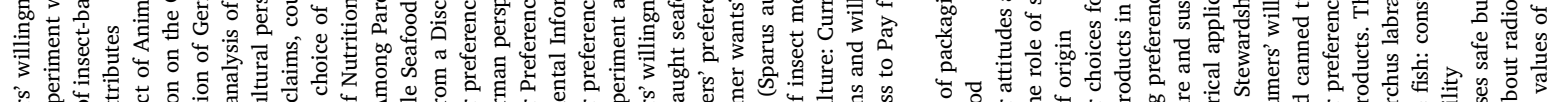

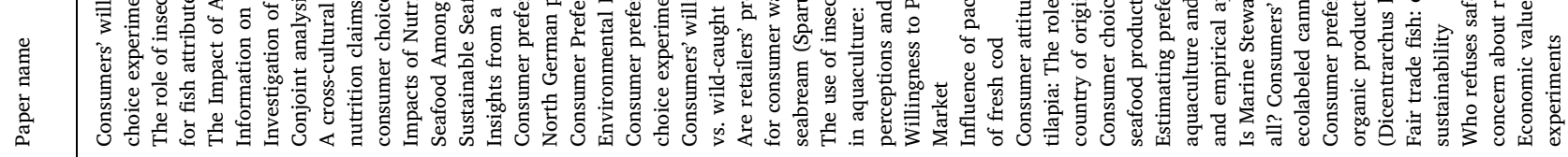

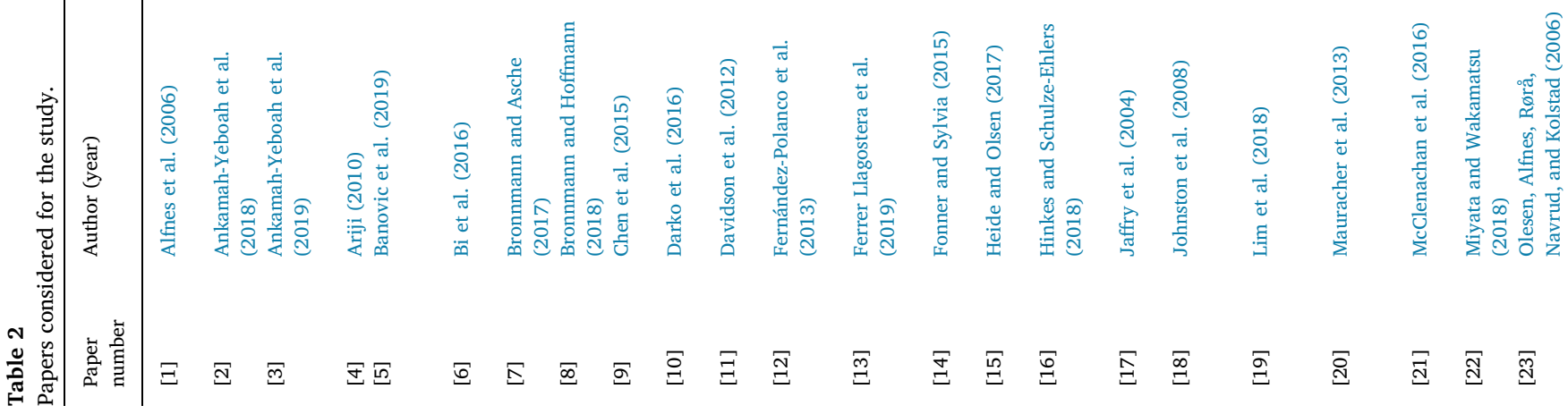




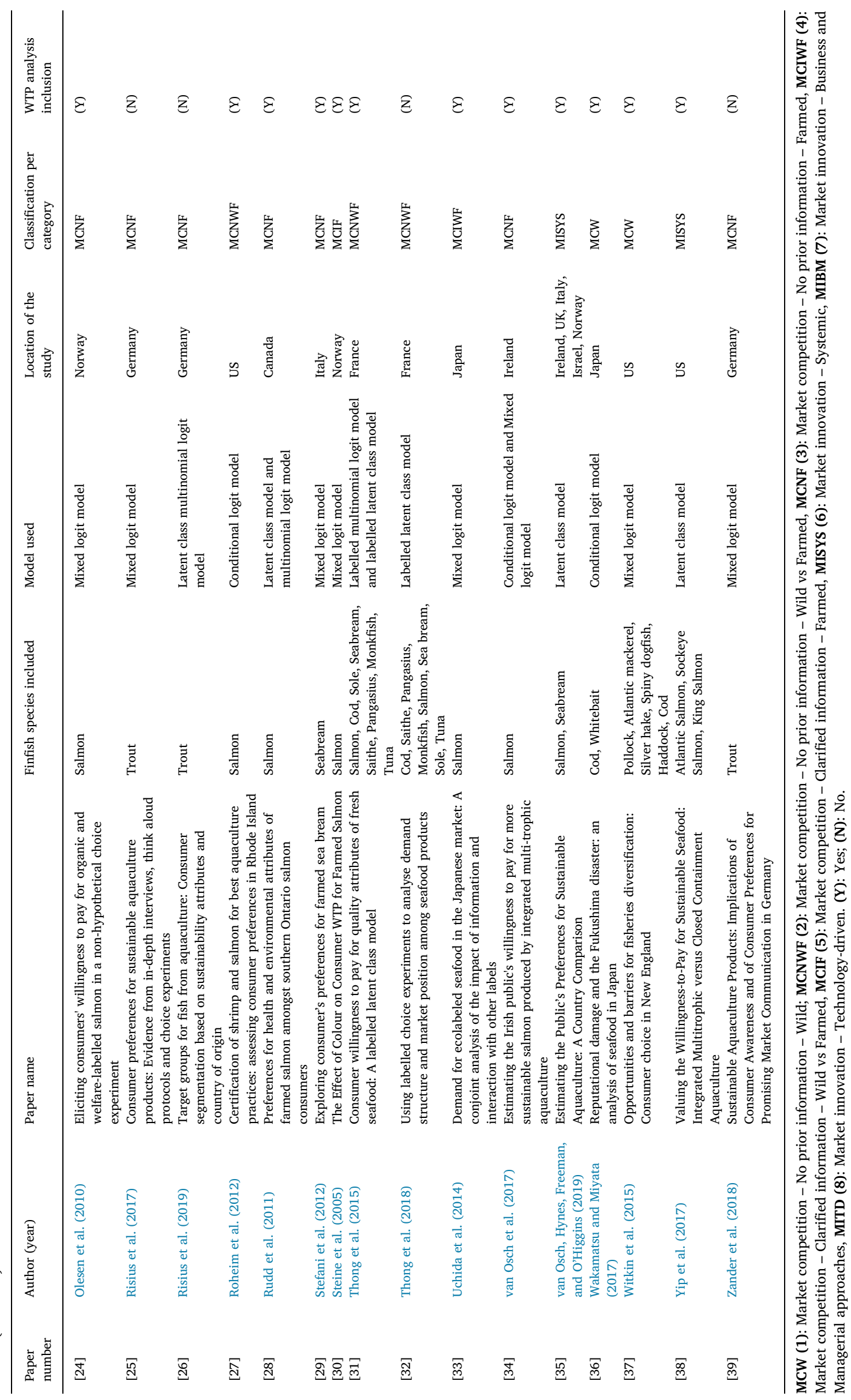




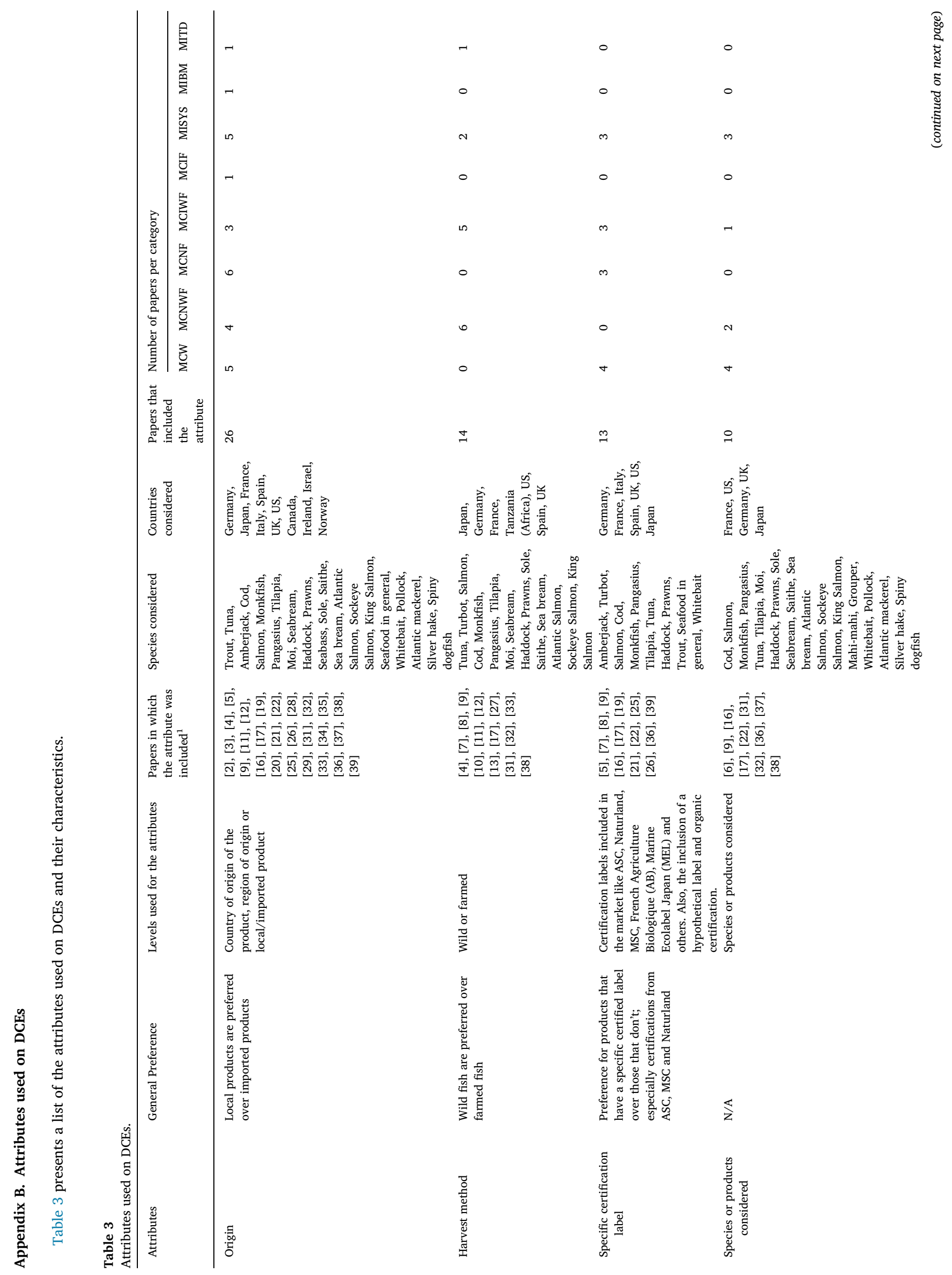




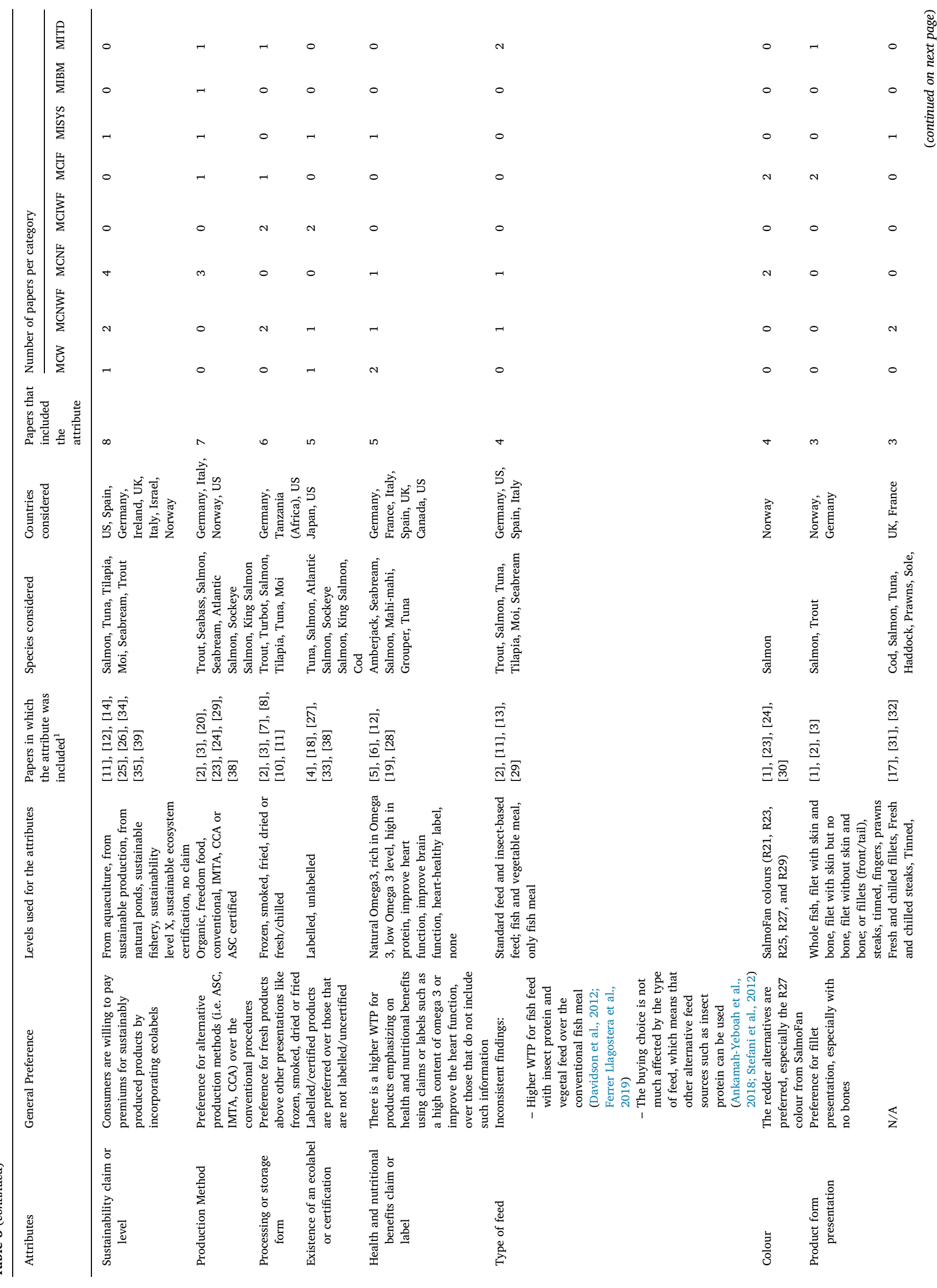




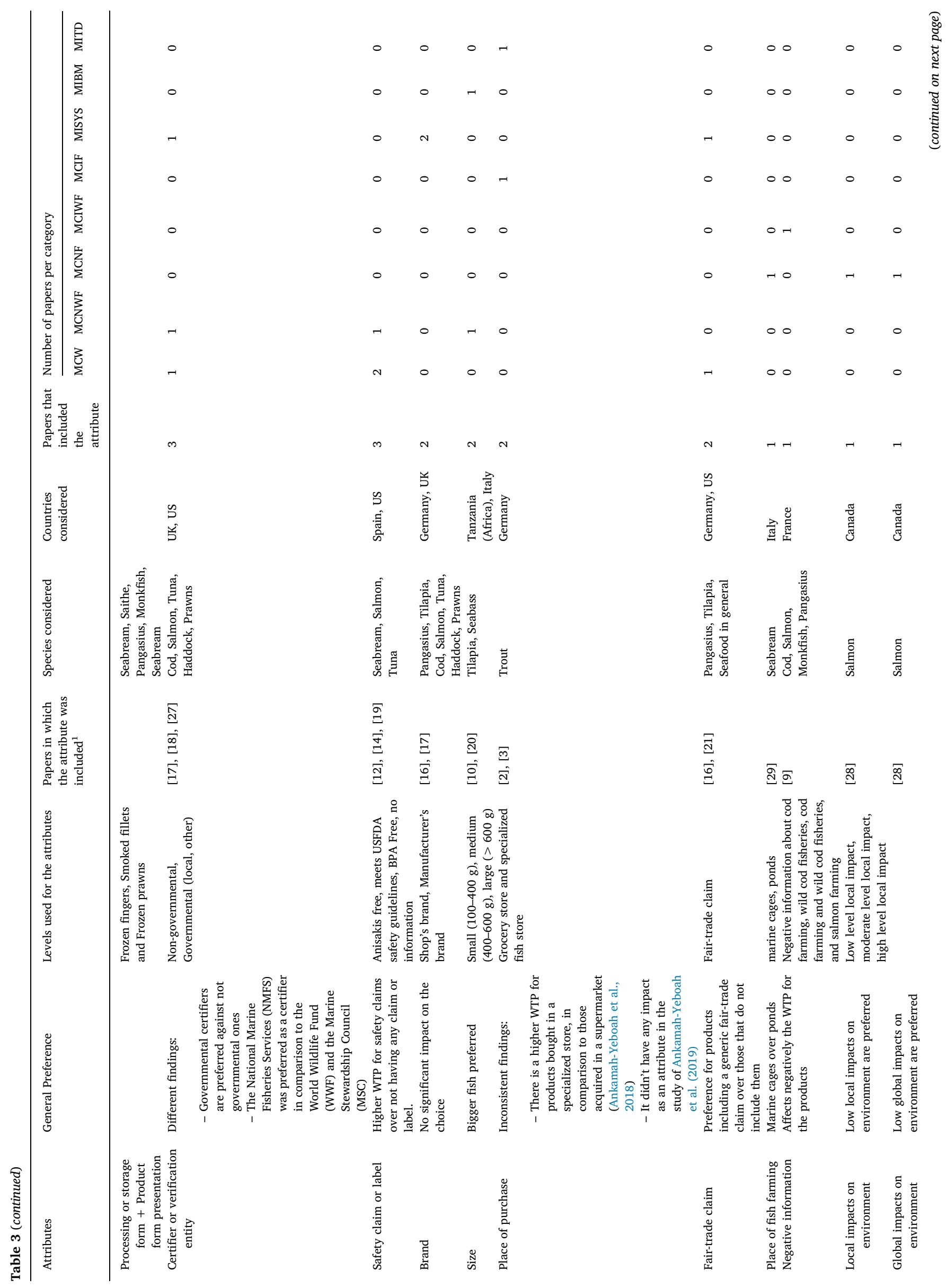




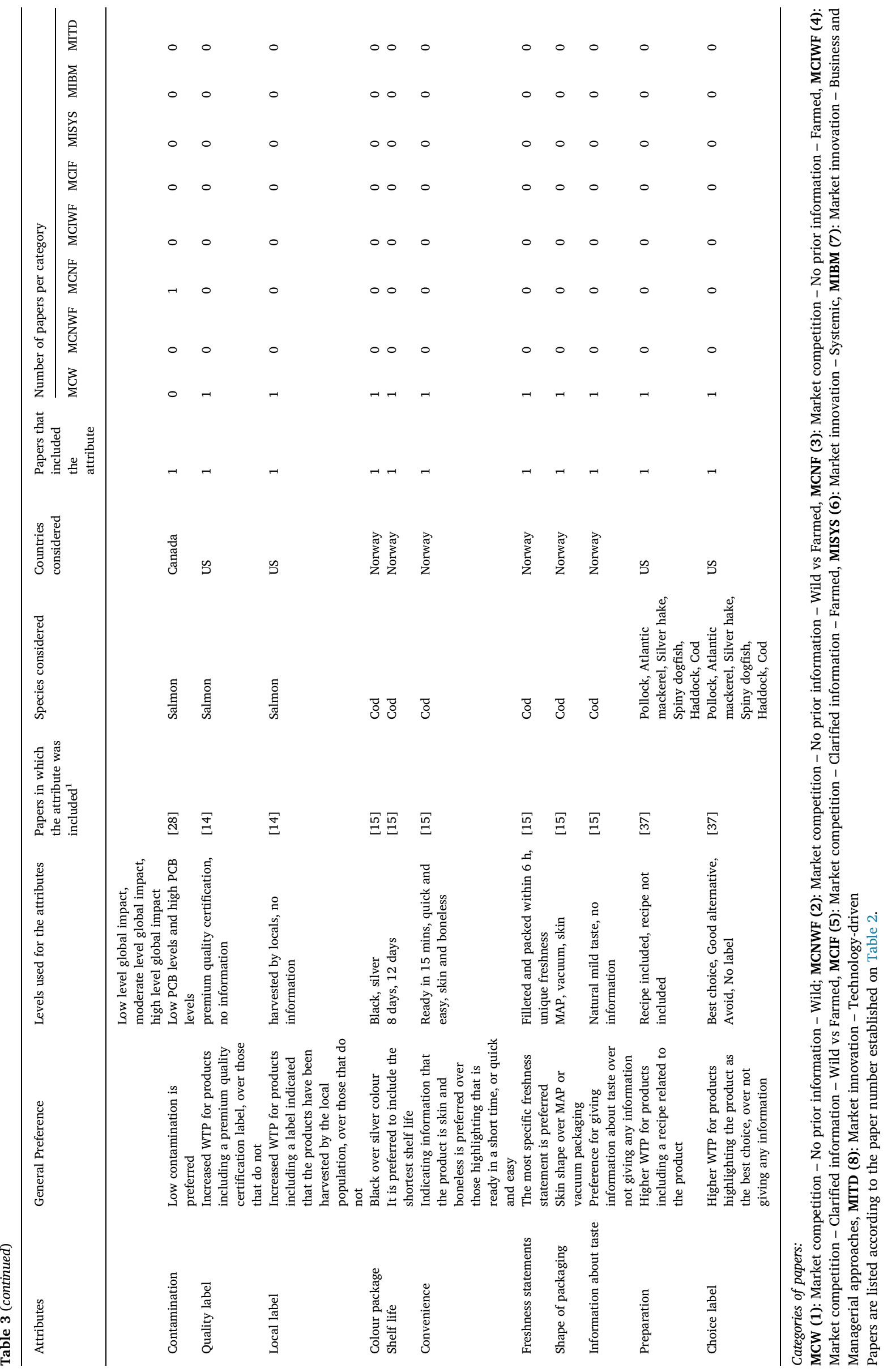




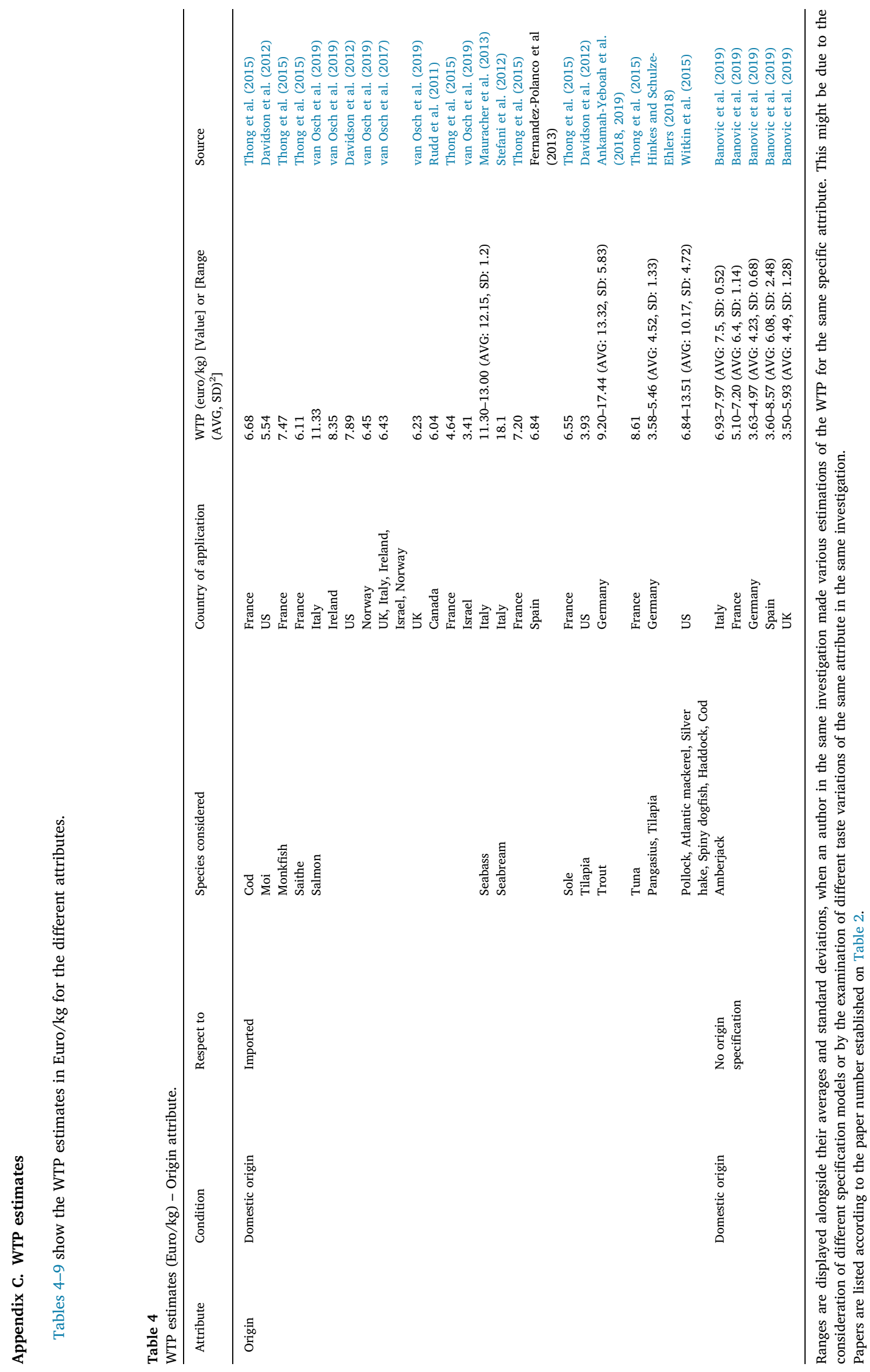




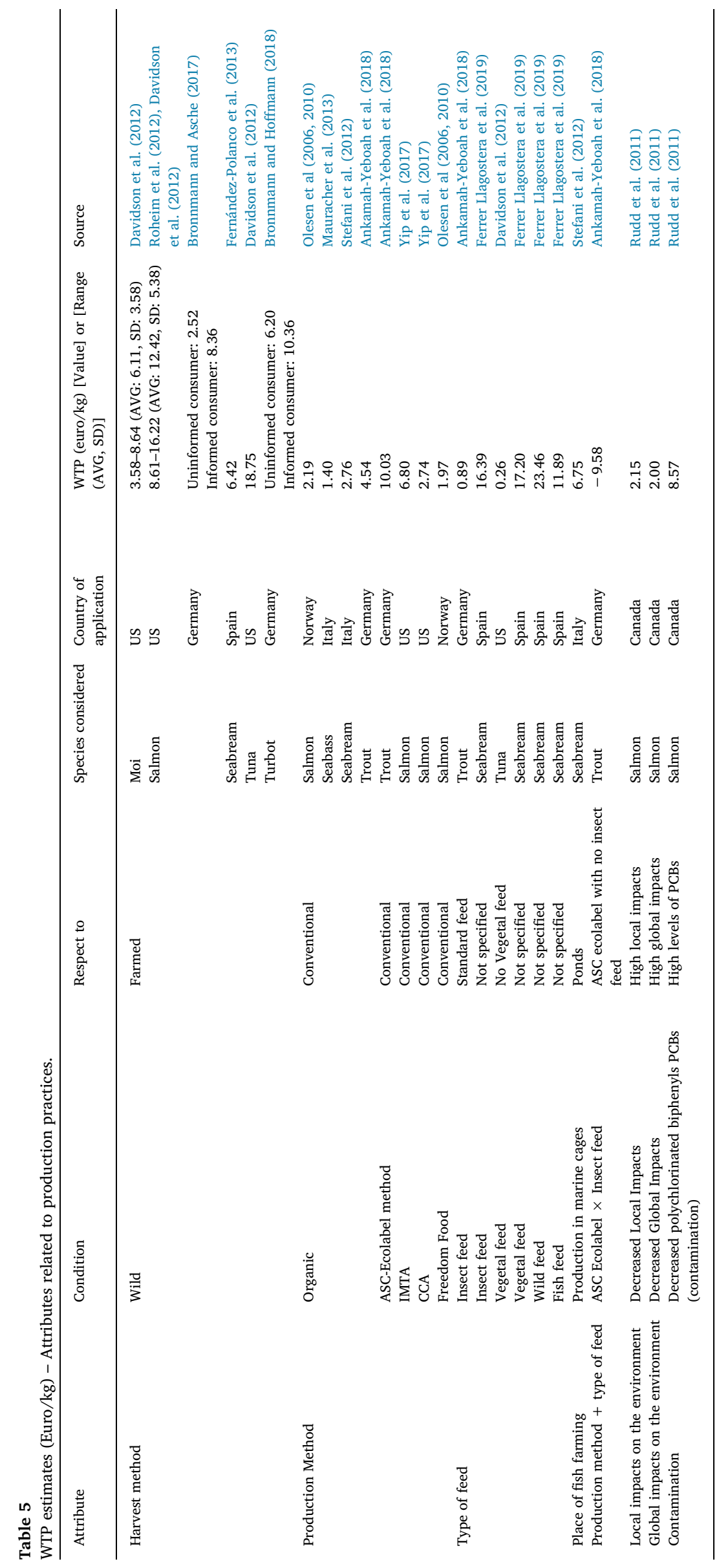




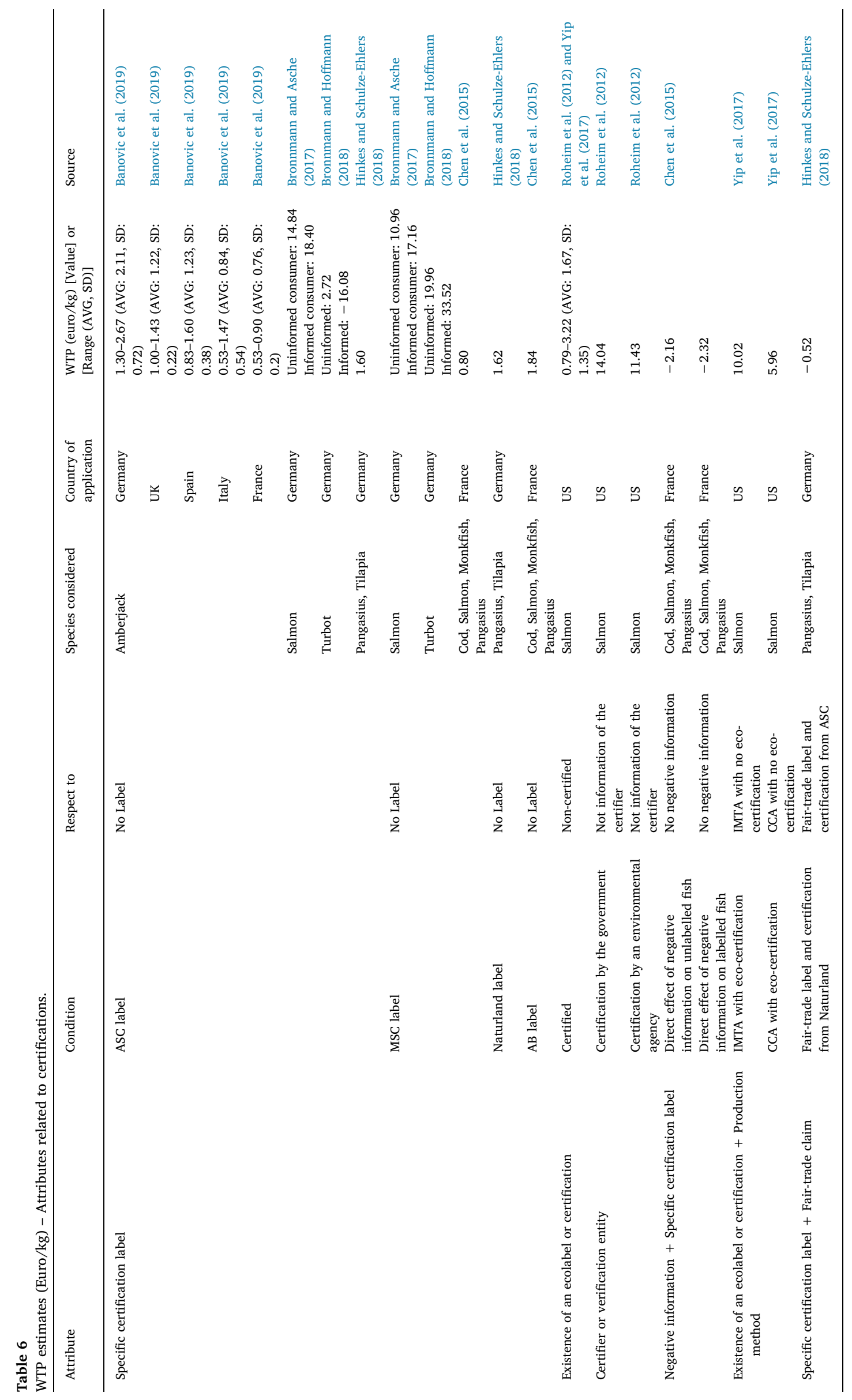




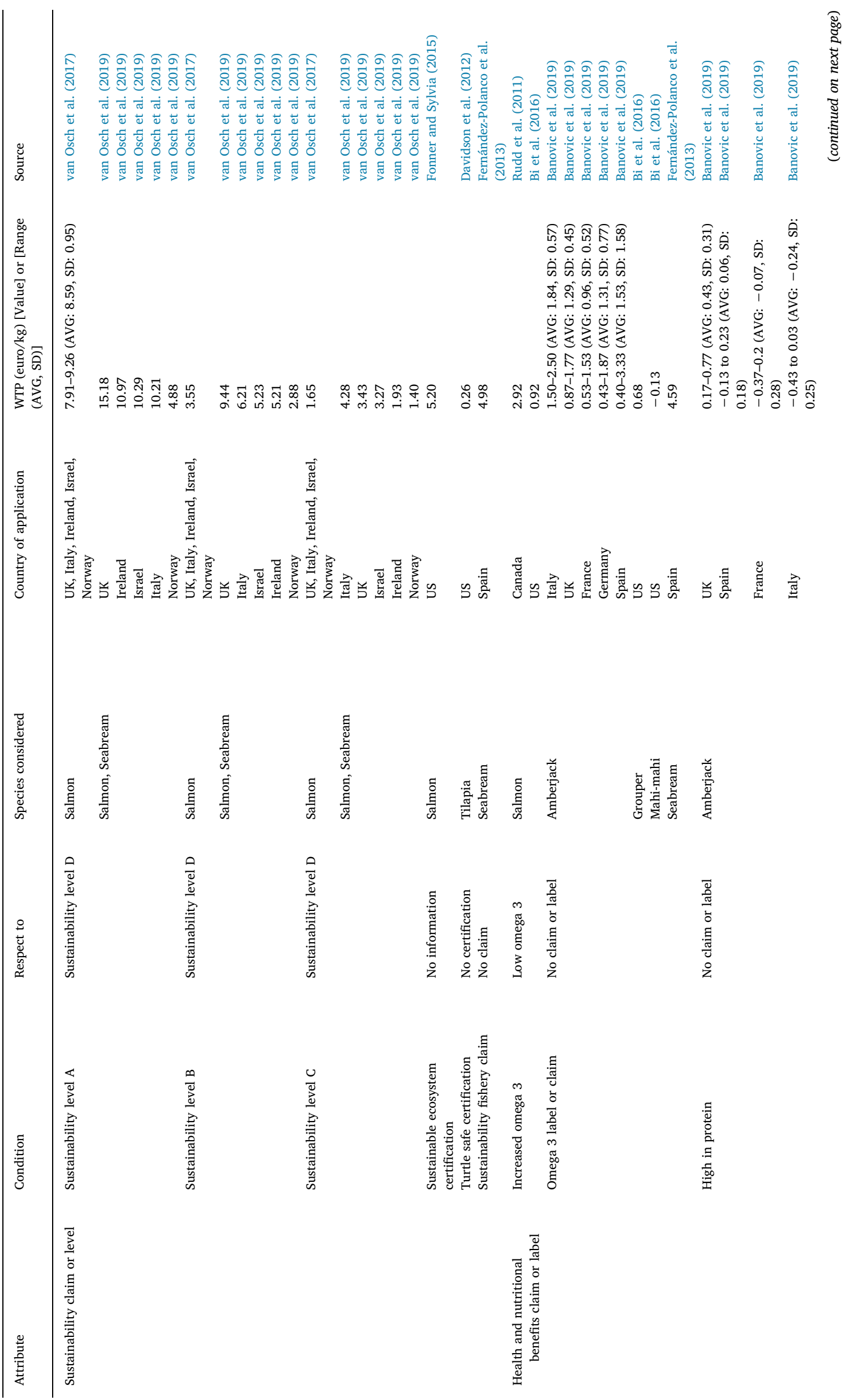




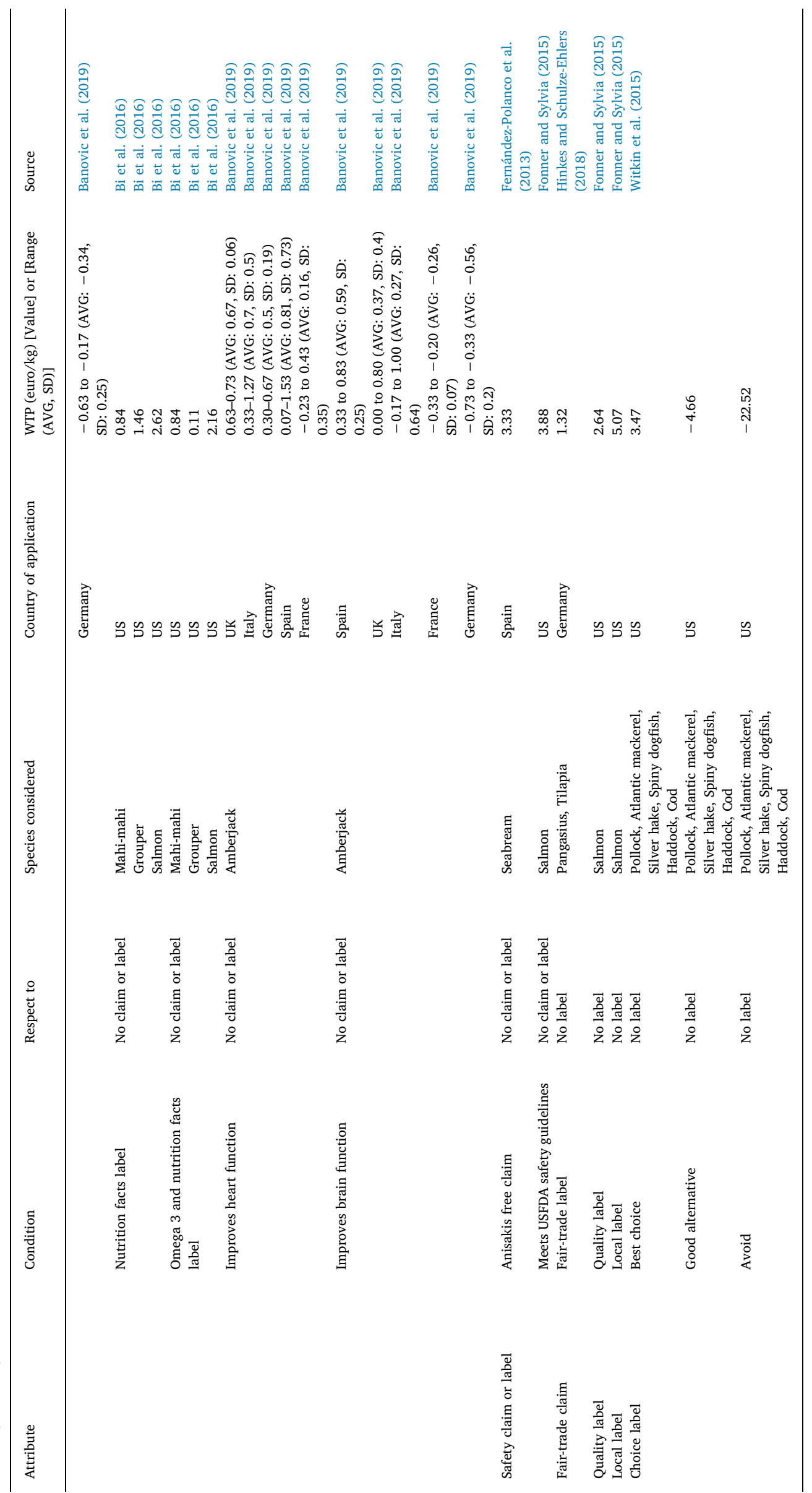




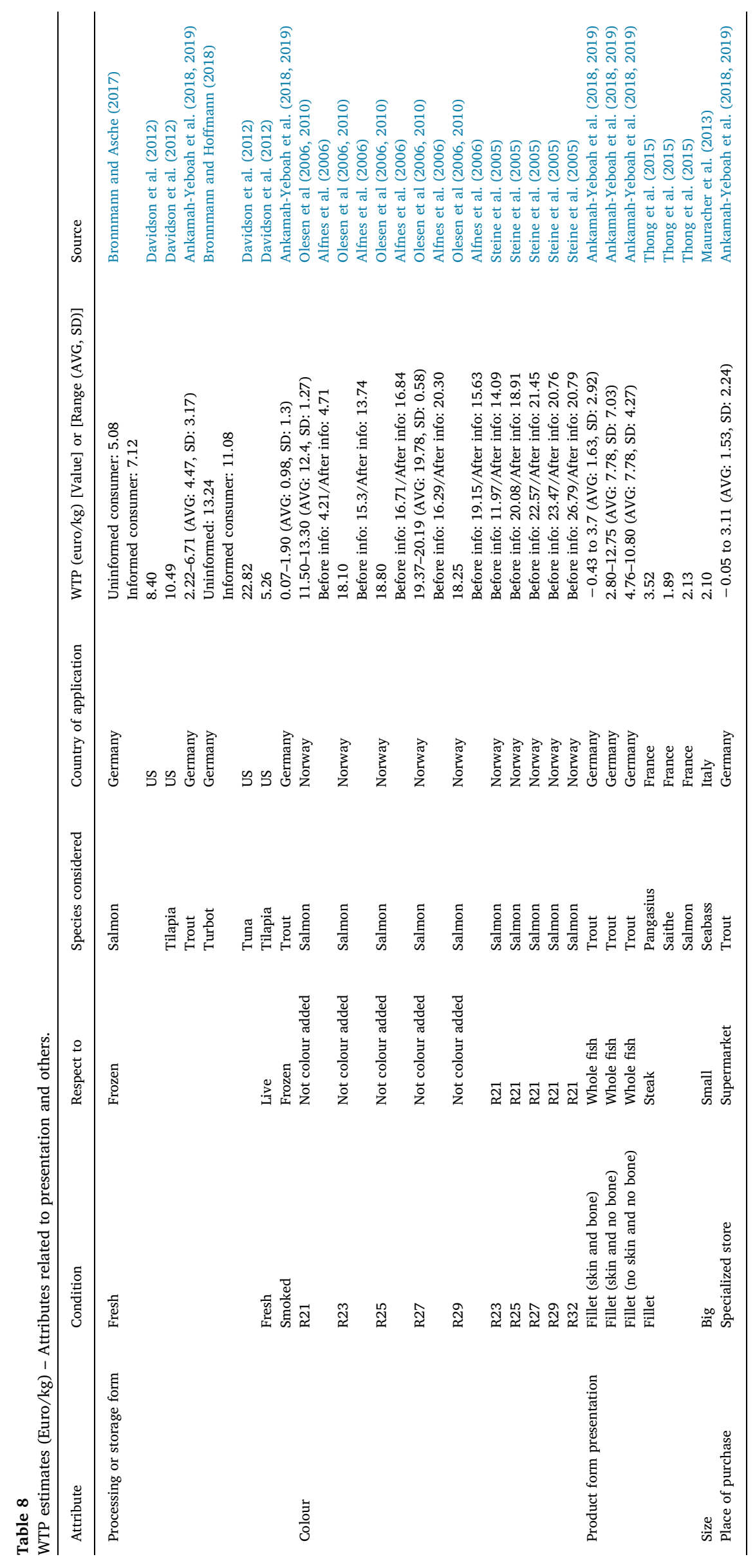




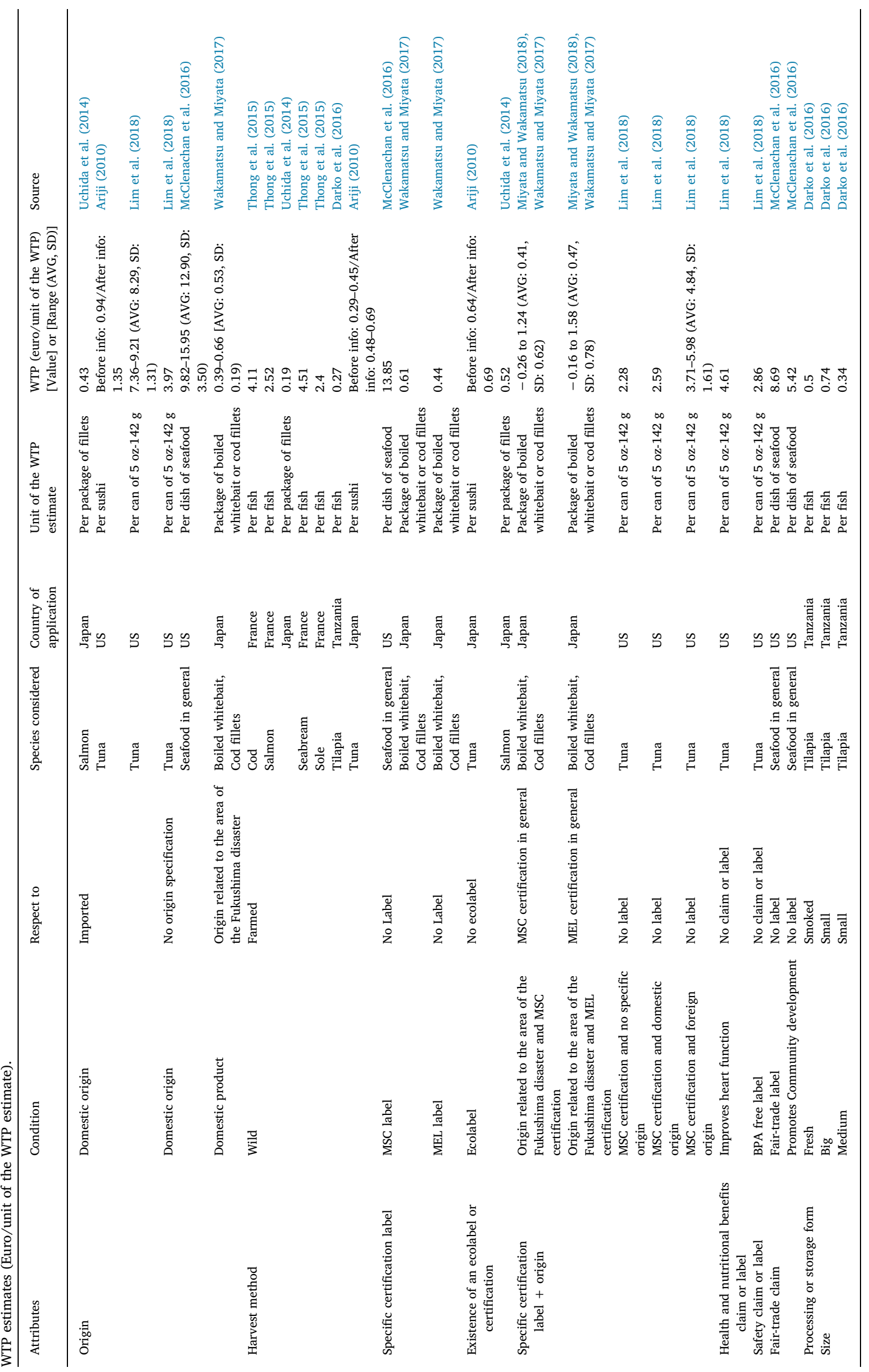




\section{References}

Alfnes, F., Guttormsen, A. G., Steine, G., \& Kolstad, K. (2006). Consumers' willingness to pay for the color of salmon: A choice experiment with real economic incentives. American Journal of Agricultural Economics, 88, 1050-1061. https://doi.org/10.1111/ j.1467-8276.2006.00915.x.

Altintzoglou, T., Verbeke, W., Vanhonacker, F., \& Luten, J. (2010). The image of fish from aquaculture among Europeans: Impact of exposure to balanced information. Journal of Aquatic Food Product Technology, 19, 103-119. https://doi.org/10.1080/ 10498850.2010 .492093$.

Ankamah-Yeboah, I., Jacobsen, J. B., \& Olsen, S. B. (2018). Innovating out of the fishmeal trap: The role of insect-based fish feed in consumers' preferences for fish attributes. British Food Journal, 120, 2395-2410. https://doi.org/10.1108/BFJ-11-2017-0604.

Ankamah-Yeboah, I., Jacobsen, J. B., Olsen, S. B., Nielsen, M., \& Nielsen, R. (2019). The impact of animal welfare and environmental information on the choice of organic fish: An empirical investigation of German trout consumers. Marine Resource Economics, 34, 248-266. https://doi.org/10.1086/705235.

Ariji, M. (2010). Conjoint analysis of consumer preference for bluefin tuna. Fisheries Science, 76, 1023-1028. https://doi.org/10.1007/s12562-010-0297-4.

Banfi, S., Farsi, M., Filippini, M., \& Jakob, M. (2008). Willingness to pay for energy-saving measures in residential buildings. Energy Economics, 30, 503-516. https://doi.org/10. 1016/j.eneco.2006.06.001.

Banovic, M., Reinders, M. J., Claret, A., Guerrero, L., \& Krystallis, A. (2019). A crosscultural perspective on impact of health and nutrition claims, country-of-origin and eco-label on consumer choice of new aquaculture products. Food Research International, 123, 36-47. https://doi.org/10.1016/j.foodres.2019.04.031.

Becker, G. S. (1965). A Theory of the allocation of time. The Economic Journal, 75, 493-517. https://doi.org/10.2307/2228949.

Ben-Elia, E., \& Shiftan, Y. (2010). Which road do I take? A learning-based model of routechoice behavior with real-time information. Transportation Research Part A: Policy and Practice, 44, 249-264. https://doi.org/10.1016/j.tra.2010.01.007.

Bi, X., House, L., \& Gao, Z. (2016). Impacts of nutrition information on choices of fresh seafood among parents. Marine Resource Economics, 31, 355-372. https://doi.org/10. $1086 / 686714$.

Booth, A. (2006). Clear and present questions: Formulating questions for evidence based practice. Library Hi Tech, 24, 355-368. https://doi.org/10.1108/ 07378830610692127.

Branson, E. J., \& Turnbull, T. (2008). Welfare and deformities in fish. Fish welfare (pp. 202-216). Blackwell Publishing Ltd. https://doi.org/10.1002/9780470697610.ch13.

Bronnmann, J., \& Asche, F. (2017). Sustainable seafood from aquaculture and wild fisheries: Insights from a discrete choice experiment in germany. Ecological Economics, 142, 113-119. https://doi.org/10.1016/j.ecolecon.2017.06.005.

Bronnmann, J., \& Hoffmann, J. (2018). Consumer preferences for farmed and ecolabeled turbot: A North German perspective. Aquaculture Economics \& Management, 22, 342-361. https://doi.org/10.1080/13657305.2018.1398788.

Carlucci, D., Nocella, G., De Devitiis, B., Viscecchia, R., Bimbo, F., \& Nardone, G. (2015). Consumer purchasing behaviour towards fish and seafood products. Patterns and insights from a sample of international studies. Appetite, 84, 212-227. https://doi. org/10.1016/j.appet.2014.10.008.

Chen, X., Alfnes, F., \& Rickertsen, K. (2015). Consumer preferences, ecolabels, and effects of negative environmental information. AgBioForum, 18, 327-336.

Claret, A., Guerrero, L., Aguirre, E., Rincón, L., Hernández, M. D., Martínez, I., .. Rodríguez-Rodríguez, C. (2012). Consumer preferences for sea fish using conjoint analysis: Exploratory study of the importance of country of origin, obtaining method, storage conditions and purchasing price. Food Quality and Preference, 26, 259-266. https://doi.org/10.1016/j.foodqual.2012.05.006.

Claret, A., Guerrero, L., Ginés, R., Grau, A., Hernández, M. D., Aguirre, E., ... RodríguezRodríguez, C. (2014). Consumer beliefs regarding farmed versus wild fish. Appetite, 79, 25-31. https://doi.org/10.1016/j.appet.2014.03.031.

Clark, M., Determann, D., Petrou, S., Moro, D., \& de Bekker-Grob, E. (2014). Discrete choice experiments in health economics: A review of the literature. Pharmacoeconomics, 32(9), 883-902. https://doi.org/10.1007/s40273-014-0170-x.

Darko, F. A., Quagrainie, K. K., \& Chenyambuga, S. (2016). Consumer preferences for farmed tilapia in Tanzania: A choice experiment analysis. Journal of Applied Aquaculture, 28, 131-143. https://doi.org/10.1080/10454438.2016.1169965.

Davidson, K., Pan, M., Hu, W., \& Poerwanto, D. (2012). Consumers' willingness to pay for aquaculture fish products vs. wild-caught seafood - A case study in Hawaii. Aquaculture Economics \& Management, 16, 136-154. https://doi.org/10.1080/ 13657305.2012 .678554

de Bekker-Grob, E, Ryan, M, \& Gerard, K (2012). Discrete choice experiments in health economics: A review of the literature. Health Economics, 21(2), 145-172. https://doi. org/10.1002/hec.1697.

Domencich, T. A., \& McFadden, D. (1975). Urban travel demand - A behavioral analysis.

Fabinyi, M., Liu, N., Song, Q., \& Li, R. (2016). Aquatic product consumption patterns and perceptions among the Chinese middle class. Regional Studies in Marine Science, 7, 1-9. https://doi.org/10.1016/j.rsma.2016.01.013.

FAO (2018a). The state of world fisheries and aquaculture 2018: Meeting the sustainable development goals, the state of world fisheries and aquaculture. Rome, Italy: FAO.

FAO (2018b). FAO yearbook. Fishery and aquaculture statistics. Rome, Italy: Food \& Agriculture Org.

Fernández-Polanco, J., Loose, S. M., \& Luna, L. (2013). Are retailers' preferences for seafood attributes predictive for consumer wants? Results from a choice experiment for seabream (Sparus aurata). Aquaculture Economics \& Management, 17, 103-122. https://doi.org/10.1080/13657305.2013.772262.

Ferrer Llagostera, P., Kallas, Z., Reig, L., \& Amores de Gea, D. (2019). The use of insect meal as a sustainable feeding alternative in aquaculture: Current situation, Spanish consumers' perceptions and willingness to pay. Journal of Cleaner Production, 229, 10-21. https://doi.org/10.1016/j.jclepro.2019.05.012.

Fonner, R., \& Sylvia, G. (2015). Willingness to pay for multiple seafood labels in a niche market. Marine Resource Economics, 30, 51-70. https://doi.org/10.1086/679466.

González, R. M., Román, C., Amador, F. J., Rizzi, L. I., de Ortúzar, J. D., Espino, R., .. Martín, J. C. (2018). Estimating the value of risk reductions for car drivers when pedestrians are involved: A case study in Spain. Transportation, 45, 499-521. https:// doi.org/10.1007/s11116-016-9736-0.

Haghiri, M. (2014). An evaluation of consumers' preferences for certified farmed Atlantic salmon. British Food Journal, 116, 1092-1105. https://doi.org/10.1108/BFJ-112012-0289.

Hall, T. E., \& Amberg, S. M. (2013). Factors influencing consumption of farmed seafood products in the Pacific northwest. Appetite, 66, 1-9. https://doi.org/10.1016/j.appet. 2013.02.012.

Heide, M., \& Olsen, S. O. (2017). Influence of packaging attributes on consumer evaluation of fresh cod. Food Quality and Preference, 60, 9-18. https://doi.org/10.1016/j. foodqual.2017.02.015.

Hill, J. I., Nelson, R. G., Woods, K. L., Weese, J. O., \& Whitis, G. N. (2013). Consumer preferences for attributes of catfish nuggets: Price, breading color, cooking method, and country of origin. Aquaculture Economics and Management, 17, 123-147. https:// doi.org/10.1080/13657305.2013.772263.

Hinkes, C., \& Schulze-Ehlers, B. (2018). Consumer attitudes and preferences towards pangasius and tilapia: The role of sustainability certification and the country of origin. Appetite, 127, 171-181. https://doi.org/10.1016/j.appet.2018.05.001.

Hoyos, D. (2010). The state of the art of environmental valuation with discrete choice experiments. Ecological Economics, 69, 1595-1603. https://doi.org/10.1016/j. ecolecon.2010.04.011.

Jaffry, S., Pickering, H., Ghulam, Y., Whitmarsh, D., \& Wattage, P. (2004). Consumer choices for quality and sustainability labelled seafood products in the UK. Food Policy, 29, 215-228. https://doi.org/10.1016/j.foodpol.2004.04.001.

Jensen, A. F., Cherchi, E., \& Mabit, S. L. (2013). On the stability of preferences and attitudes before and after experiencing an electric vehicle. Transportation Research Part D: Transport and Environment, 25, 24-32. https://doi.org/10.1016/j.trd.2013.07.006.

Joffre, O. M., Klerkx, L., Dickson, M., \& Verdegem, M. (2017). How is innovation in aquaculture conceptualized and managed? A systematic literature review and reflection framework to inform analysis and action. Aquaculture, 470, 129-148. https:// doi.org/10.1016/j.aquaculture.2016.12.020.

Johnston, R. J., Roheim, C. A., Joglekar, D. P., \& Pomeroy, R. S. (2008). Estimating preferences for non-market attributes of aquaculture and sustainable seafood production: Methods and empirical applications. IJEP, 33, 469. https://doi.org/10. 1504/IJEP.2008.020573.

Kelly, J., Haider, W., Williams, P. W., \& Englund, K. (2007). Stated preferences of tourists for eco-efficient destination planning options. Tourism Management, 28, 377-390. https://doi.org/10.1016/j.tourman.2006.04.015.

Lancaster, K. J. (1966). A new approach to consumer theory. Journal of Political Economy, 74, 132-157.

Lembo, G., Jokumsen, A., Spedicato, M. T., Facchini, M. T., \& Bitetto, I. (2018). Assessing stakeholder's experience and sensitivity on key issues for the economic growth of organic aquaculture production. Marine Policy, 87, 84-93. https://doi.org/10.1016/j. marpol.2017.10.005.

Lim, K. H., Hu, W., \& Nayga, R. M. (2018). Is Marine Stewardship Council's ecolabel a rising tide for all? Consumers' willingness to pay for origin-differentiated ecolabeled canned tuna. Marine Policy, 96, 18-26. https://doi.org/10.1016/j.marpol.2018.07. 015.

Louviere, J. J., Flynn, T. N., \& Carson, R. T. (2010). Discrete choice experiments are not conjoint analysis. Journal of Choice Modelling, 3, 57-72. https://doi.org/10.1016/ S1755-5345(13)70014-9.

Louviere, J. J., Hensher, D. A., Swait, J. D., \& Adamowicz, W. (2000). Stated choice Methods by Jordan J. Louviere [WWW Document]. Cambridge Corehttps://doi.org/10. 1017/CBO9780511753831.

Luomala, H. T. (2007). Exploring the role of food origin as a source of meanings for consumers and as a determinant of consumers' actual food choices. Journal of Business Research, The 8th International Forum on the Sciences Techniques and Art applied to Marketing, 60, 122-129. https://doi.org/10.1016/j.jbusres.2006.10.010.

Martín, J. C., Román, C., \& Mendoza, C. (2018). Determinants for sun-and-beach selfcatering accommodation selection: A stated preference approach. Tourism Economics, 24, 319-336. https://doi.org/10.1177/1354816618758731.

Mauracher, C., Tempesta, T., \& Vecchiato, D. (2013). Consumer preferences regarding the introduction of new organic products. The case of the Mediterranean sea bass (Dicentrarchus labrax) in Italy. Appetite, 63, 84-91. https://doi.org/10.1016/j.appet. 2012.12.009.

McClenachan, L., Dissanayake, S. T. M., \& Chen, X. (2016). Fair trade fish: Consumer support for broader seafood sustainability. Fish and Fisheries, 17, 825-838. https:// doi.org/10.1111/faf.12148.

McFadden, D. (1981). Econometric MODELS for probabilistic choice. Structural analysis of discrete data with econometric applications 198272.

McFadden, D. (1974). Conditional logit analysis of qualitative choice behavior. Frontiers in econometrics. New York: Academic Press105-142.

Miyata, T., \& Wakamatsu, H. (2018). Who refuses safe but stigmatized marine products due to concern about radioactive contamination? Fisheries Science, 84, 1119-1133. https://doi.org/10.1007/s12562-018-1250-1.

Moher, D., Liberati, A., Tetzlaff, J., Altman, D. G., \& PRISMA Group (2009). Preferred reporting items for systematic reviews and meta-analyses: The PRISMA statement. PLoS Medicine, 6, e1000097. https://doi.org/10.1371/journal.pmed.1000097.

Olesen, I., Alfnes, F., Røra, M. B., \& Kolstad, K. (2010). Eliciting consumers' willingness to 
pay for organic and welfare-labelled salmon in a non-hypothetical choice experiment. Livestock Science, 127, 218-226. https://doi.org/10.1016/j.livsci.2009.10.001.

Olesen, I., Alfnes, F., Rørå, M. B., Navrud, S., \& Kolstad, K. (2006). Economic values of fish welfare and application of market experiments. Ethics and the politics of food: Preprints of the 6th congress of the European Society for Agricultural and Food Ethics (pp. 446-451). . https://doi.org/10.3920/978-90-8686-575-8.

Ortega, D. L., Wang, H. H., Wu, L., \& Olynk, N. J. (2011). Modeling heterogeneity in consumer preferences for select food safety attributes in China. Food Policy, 36, 318-324. https://doi.org/10.1016/j.foodpol.2010.11.030.

Polymeros, K., Kaimakoudi, E., Schinaraki, M., \& Batzios, C. (2015). Analysing consumers' perceived differences in wild and farmed fish. British Food Journal, 117, 1007-1016. https://doi.org/10.1108/BFJ-12-2013-0362.

Ramalho Ribeiro, A., Altintzoglou, T., Mendes, J., Nunes, M. L., Dinis, M. T., \& Dias, J. (2019). Farmed fish as a functional food: Perception of fish fortification and the in fluence of origin - Insights from Portugal. Aquaculture, 501, 22-31. https://doi.org/ 10.1016/j.aquaculture.2018.11.002.

Rigby, D., \& Burton, M. (2005). Preference heterogeneity and GM food in the UK. European Review of Agricultural Economics, 32, 269-288. https://doi.org/10.1093/ eurrag/jbi009.

Risius, A., Hamm, U., \& Janssen, M. (2019). Target groups for fish from aquaculture: Consumer segmentation based on sustainability attributes and country of origin Aquaculture, 499, 341-347. https://doi.org/10.1016/j.aquaculture.2018.09.044.

Risius, A., Janssen, M., \& Hamm, U. (2017). Consumer preferences for sustainable aquaculture products: Evidence from in-depth interviews, think aloud protocols and choice experiments. Appetite, 113, 246-254. https://doi.org/10.1016/j.appet.2017. 02.021 .

Rizzi, L. I., \& Ortúzar, J. de D. (2003). Stated preference in the valuation of interurban road safety. Accident Analysis \& Prevention, 35, 9-22. https://doi.org/10.1016/S00014575(01)00082-3.

Robinson, P., \& Lowe, J. (2015). Literature reviews vs systematic reviews. 103-103 Australian and New Zealand Journal of Public Health, 39. https://doi.org/10.1111/ 1753-6405.12393.

Roheim, C. A., Sudhakaran, P. O., \& Durham, C. A. (2012). Certification of shrimp and salmon for best aquaculture practices: Assessing consumer preferences in Rhode Island. AquacultureEconomics and Management, 16, 266-286. https://doi.org/10. 1080/13657305.2012.713075.

Rudd, M. A., Pelletier, N., \& Tyedmers, P. (2011). Preferences for health and environmental attributes of farmed salmon amongst southern ontario salmon consumers. Aquaculture Economics and Management, 15, 18-45. https://doi.org/10.1080/ 13657305.2011 .549405

Schlag, A. K., \& Ystgaard, K. (2013). Europeans and aquaculture: Perceived differences between wild and farmed fish. British Food Journal, 115, 209-222. https://doi.org/10. 1108/00070701311302195.

Stefani, G., Scarpa, R., \& Cavicchi, A. (2012). Exploring consumer's preferences for farmed sea bream. Aquaculture International, 20, 673-691. https://doi.org/10.1007/ s10499-011-9495-z.

Steine, G., Alfnes, F., \& Rørå, M. B. (2005). The effect of color on consumer WTP for farmed salmon. Marine Resource Economics, 20, 211-219. https://doi.org/10.1086/ mre.20.2.42629470

Thong, N. T., \& Solgaard, H. S. (2017). Consumer's food motives and seafood consumption. Food Quality and Preference, 56, 181-188. https://doi.org/10.1016/j.foodqual. 2016.10.008.

Thong, N. T., Solgaard, H. S., Haider, W., Roth, E., \& Ravn-Jonsen, L. (2018). Using labeled choice experiments to analyze demand structure and market position among seafood products. Agribusiness, 34, 163-189. https://doi.org/10.1002/agr.21504.

Thong, T. N., Haider, W., Solgaard, H. S., Ravn-Jonsen, L., \& Roth, E. (2015). Consumer willingness to pay for quality attributes of fresh seafood: A labeled latent class model. Food Quality and Preference, 41, 225-236. https://doi.org/10.1016/j.foodqual.2014. 12.007.

Thurstone, L. L. (1927). A law of comparative judgment. Psychological Review, 34, 273-286. https://doi.org/10.1037/h0070288.

Tomić, M., Lucević, Z., Tomljanović, T., \& Matulić, D. (2017). Wild-caught versus farmed fish - Consumer perception. Croatian Journal of Fisheries, 75, 41-50. https://doi.org/ 10.1515/cjf-2017-0007.
Train, K. (2009). Discrete choice methods with simulation (Cambridge books). Cambridge University Press.

Uchida, H., Onozaka, Y., Morita, T., \& Managi, S. (2014). Demand for ecolabeled seafood in the Japanese market: A conjoint analysis of the impact of information and interaction with other labels. Food Policy, 44, 68-76. https://doi.org/10.1016/j.foodpol. 2013.10.002.

van Osch, S., Hynes, S., Freeman, S., \& O'Higgins, T. (2019). Estimating the public's preferences for sustainable aquaculture: A country comparison. Sustainability, 11, 569. https://doi.org/10.3390/su11030569.

van Osch, S., Hynes, S., O'Higgins, T., Hanley, N., Campbell, D., \& Freeman, S. (2017). Estimating the Irish public's willingness to pay for more sustainable salmon produced by integrated multi-trophic aquaculture. Marine Policy, 84, 220-227. https://doi.org/ 10.1016/j.marpol.2017.07.005.

Vanhonacker, F., Altintzoglou, T., Luten, J., \& Verbeke, W. (2011). Does fish origin matter to European consumers?: Insights from a consumer survey in Belgium, Norway and Spain. British Food Journal, 113, 535-549. https://doi.org/10.1108/ 00070701111124005.

Vecchio, R., \& Cavallo, C. (2019). Increasing healthy food choices through nudges: A systematic review. Food Quality and Preference, 78, 103714. https://doi.org/10.1016/ j.foodqual.2019.05.014.

Verbeke, W., Sioen, I., Brunsø, K., De Henauw, S., \& Van Camp, J. (2007). Consumer perception versus scientific evidence of farmed and wild fish: Exploratory insights from Belgium. Aquaculture International, 15, 121-136. https://doi.org/10.1007/ s10499-007-9072-7.

Verlegh, P. W. J., \& Steenkamp, J. (1999). A review and meta-analysis of country-oforigin research. Journal of Economic Psychology, 20, 521-546. https://doi.org/10. 1016/S0167-4870(99)00023-9.

Wakamatsu, H., \& Miyata, T. (2017). Reputational damage and the Fukushima disaster: An analysis of seafood in Japan. Fisheries Science, 83, 1049-1057. https://doi.org/10 1007/s12562-017-1129-6.

Wang, F., Zhang, J., Mu, W., Fu, Z., \& Zhang, X. (2009). Consumers' perception toward quality and safety of fishery products, Beijing, China. Food Control, 20, 918-922. https://doi.org/10.1016/j.foodcont.2009.01.008.

Whitmarsh, D., \& Palmieri, M. G. (2011). Consumer behaviour and environmental preferences: A case study of Scottish salmon aquaculture. Aquaculture Research, 42, 142-147. https://doi.org/10.1111/j.1365-2109.2010.02672.x.

Whitmarsh, D., \& Palmieri, M. G. (2009). Social acceptability of marine aquaculture: The use of survey-based methods for eliciting public and stakeholder preferences. Marine Policy, 33, 452-457. https://doi.org/10.1016/j.marpol.2008.10.003.

Wilson, A. L., Buckley, E., Buckley, J. D., \& Bogomolova, S. (2016). Nudging healthier food and beverage choices through salience and priming. Evidence from a systematic review. Food Quality and Preference, 51, 47-64. https://doi.org/10.1016/j.foodqual. 2016.02.009.

Witkin, T., Dissanayake, S. T. M., \& McClenachan, L. (2015). Opportunities and barriers for fisheries diversification: Consumer choice in New England. Fisheries Research, 168 56-62. https://doi.org/10.1016/j.fishres.2015.03.019.

Xu, P., Zeng, Y., Fong, Q., Lone, T., \& Liu, Y. (2012). Chinese consumers' willingness to pay for green- and eco-labeled seafood. Food Control, 28, 74-82. https://doi.org/10 1016/j.foodcont.2012.04.008.

Yip, W., Knowler, D., Haider, W., \& Trenholm, R. (2017). Valuing the willingness-to-pay for sustainable seafood: Integrated multitrophic versus closed containment aquaculture. Canadian Journal of Agricultural Economics/Revue canadienne d'agroeconomie, 65, 93-117. https://doi.org/10.1111/cjag.12102.

Zander, K., \& Feucht, Y. (2018). Consumers' willingness to pay for sustainable seafood made in Europe. Journal of International Food \& Agribusiness Marketing, 30, 251-275. https://doi.org/10.1080/08974438.2017.1413611.

Zander, K., Risius, A., Feucht, Y., Janssen, M., \& Hamm, U. (2018). Sustainable aquaculture products: Implications of consumer awareness and of consumer preferences for promising market communication in Germany. Journal of Aquatic Food Product Technology, 27, 5-20. https://doi.org/10.1080/10498850.2017.1390028.

Zeithaml, V. A. (1988). Consumer perceptions of price, quality, and value: A means-end model and synthesis of evidence. Journal of Marketing, 52, 2-22. https://doi.org/10. $2307 / 1251446$. 